Chemical Technology Division

\title{
LITERATURE REVIEW OF STABILIZATION/SOLIDIFICATION OF VOLATILE ORGANIC COMPOUNDS AND THE IMPLICATIONS FOR HANFORD GROUTS
}

R. D. Spence

S. C. Osborne

Date Published-September 1993

Prepared for

Westinghouse Hanford Company

(Activity No. EW 1010030 )

\author{
Prepared by the \\ OAK RIDGE NATIONAL LABORATORY \\ Oak Ridge, Tennessee 37831 \\ managed by \\ MARTIN MARIETTA ENERGY SYSTEMS, INC. \\ for the \\ U.S. DEPARTMENT OF ENERGY \\ under contract DE-AC(15-84OR214(X)
}




\section{CONTENTS}

PREFACE $\ldots \ldots \ldots \ldots \ldots \ldots \ldots \ldots \ldots \ldots \ldots \ldots \ldots \ldots \ldots \ldots \ldots \ldots \ldots \ldots \ldots \ldots$

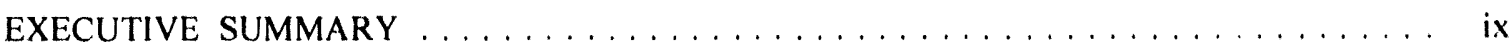

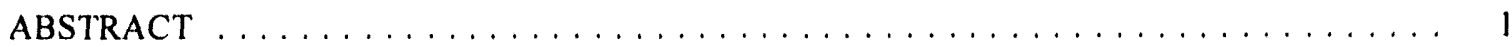

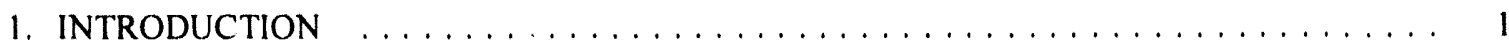

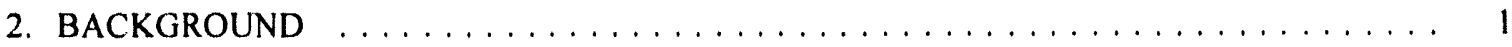

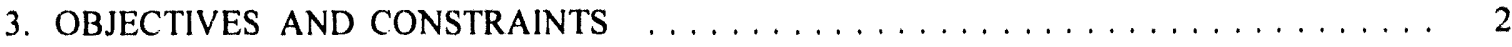

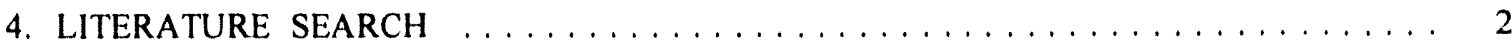

5. DISCUSSION OF THE LITERATURE $\ldots \ldots \ldots \ldots \ldots \ldots \ldots \ldots \ldots \ldots \ldots \ldots$

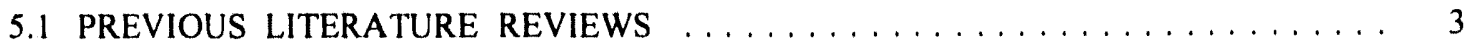

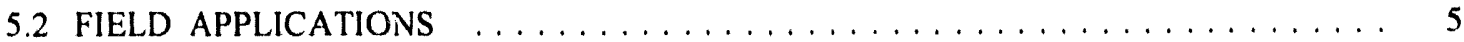

5.3 ORGANIC LOSSES DURING GROUT FORMATION $\ldots \ldots \ldots \ldots \ldots \ldots \ldots$ 7

$5.4^{\circ}$ BASIC STUDIES OF ORGANIC IMMOBILIZATION $\ldots \ldots \ldots \ldots \ldots \ldots \ldots \ldots$

6. SUMMARY AND CONCLUSIONS $\ldots \ldots \ldots \ldots \ldots \ldots \ldots \ldots \ldots \ldots \ldots \ldots \ldots$

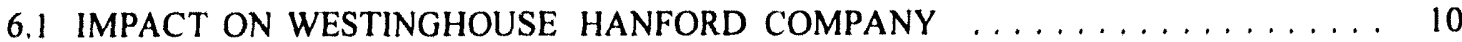

6.2 RECOMMENDATIONS FOR WESTINGHOUSE HANFORD COMPANY $\ldots \ldots \ldots 11$

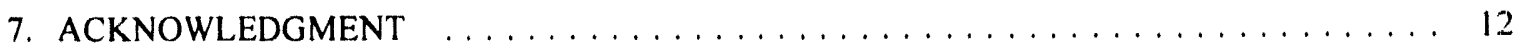

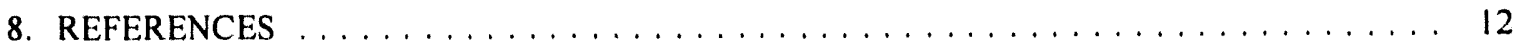

Appendix A. RESULTS OF THE COMPUTER LITERATURE SEARCH $\ldots \ldots \ldots \ldots \ldots$ A-1 


\section{ACRONYMS}

BDAT

CERCLA

DST

EPA

GTF

ORNL

OTA

RCRA

ROD

$S / S$

SARA

SITE

TCEt

TCLP

VOC

WHC best demonstrated available technology

Comprehensive Environmental Response, Compensation, and Liability Act double-shell tanks

U.S. Environmental Protection Agency

grout treatment facility

Oak Ridge National Laboratory

Office of Technology Assessment

Resource Conservation and Recovery Act

record of decision

stabilization/solidification

Superfund Amendments and Reauthorization Act

Superfund Innovation Technology Evaluation

1,1,1-trichloroethane

toxicity characteristic leaching procedure

volatile organic compound

Westinghouse Hanford Company 


\section{PREFACE}

This report meets requirements for Milestone 3.3, "Final Report (Based on Literature Findings) ut Selected Organics Treatment Options and Recommendations for Hanford Wastes," as described in Statement of Work TMG-SOW-H-91, Rev. 0, in support of the Westinghouse Hanford Grout Disposal Program. 


\section{EXECUTIVE SUMMARY}

Stabilization/solidification technology is one of the most widely used techniques for the treatment and ultimate disposal of both radioactive and chemically hazardous wastes. Cement-based products, commonly referred to as grouts, are the predominant materials of choice because of their low processing costs, compatibility with a wide variety of disposal scenarios, and ability to meet stringent processing and performance requirements. Such technology is being utilized in a grout treatment facility by the Westinghouse Hanford Company (WHC) for the disposal of various wastes located on the Hanford Reservation, including 106-AN wastes.

As of September 25, 1990, the U.S. Environmental Protection Agency (EPA) replaced the EP-Toxicity Procedure with the Toxicity Characteristic Leaching Procedure (TCLP) for determining whether a waste whose status is unknown is characteristically hazardous. This new procedure changed the status of many wastes throughout the United States from "not characteristically hazardous" to "characteristically hazardous" because several organic compounds were added to the metals and pesticides/herbicides already regulated. There was also concern that the potential presence of organics might make the Hanford grouts subject to the land-ban restrictions. WHC was concerned that the double-shell tanks supernate was potentially characteristically hazardous by TCLP definition, or subject to land-ban restrictions, because of the suspected presence of the following organics: acetone, methyl ethyl ketone, methyl isobutyl ketone, and 1,1,1-trichloroethane.

These four organics are defined as volatile organic compounds (VOCs) by EPA. (The TCLP lists extractant-concentration limits for a large number of organics not regulated by the EP-Toxicity procedure, and the limits for these four are nonlisted, $7.2 \mathrm{mg} / \mathrm{L}$, nonlisted, and $30 \mathrm{mg} / \mathrm{L}$, respectively. Land-ban restrictions limit the TCLP leachate concentration of acetone to $0.59 \mathrm{mg} / \mathrm{L}$. All four compounds are targeted for treatment under the land-ban restrictions and within the waste codes by the best demonstrated available technology (BDAT). (The BDAT reference numbers are 222, 34, 229 , and 45 , respectively.) $)^{\prime}$ Even if the supernate were not characteristically hazardous by TCLP definition, WHC was concerned that the regulators of EPA and the state of Washington might still require proof of the organic retention capabilities of the grout and engineered barriers because of the potential presence of these organics.

A literature search on stabilization/solidification of VOCs revealed three previous reviews on this topic, two covering the pre-1985 period and one covering the post-1985 period. Not all of the relevant literature was in hand at the time this report was written, but the availability of two of the reviews (including the post-1985 review) made the review fairly complete.

Stabilization/solidification has routinely been used for remediation of Superfund sites, sometimes even when organic contamination (including VOCs) was present. Despite this, stabilization/solidification of organics is not widely accepted in the regulatory community. In fact, it is not accepted for Resource Conservation and Recovery Act wastes and land-banned wastes and is under attack for Comprehensive Environmental Response, Compensation, and Liability Act and Superfund Amendments and Reauthorization Act wastes. Thus, if VOCs are present at levels of regulatory concern (doubtful at the high temperatures of the double-shell tanks waste), it is questionable that regulators will accept stabilization/solidification and subsequent burial.

There is good evidence that clays, particularly modified clays, bond or degrade organics. However, organics, especially hydrophilic organics, are generally aqueous leachable from stabilization/solidification products. The additives do help retard the leaching rate and can help the Westinghouse Hanford Company grouts retain the VOCs, but it must be assumed the VOCs will eventually be released. VOC evaporative losses do occur during processing, but a significant fraction should be retained in the waste form at normal temperatures (the high temperatures of the Westinghouse Hanford Company wastes and grouts should cause them higher losses). 
It is recommended that Westinghouse Hanford Company verify the presence of VOCs in the double-shell tanks waste, receive regulatory approval for stabilization/solidification if VOCs are present, use commercial additives for organics if VOCs are present and approval is received, and test the effectiveness of these additives before investing in them. 
ORNL/TM- 11824

\title{
LITERATURE REVIEW OF STABILIZATION/SOLIDIFICATION OF VOLATILE ORGANIC COMPOUNDS AND THE IMPLICATIONS FOR HANFORD GROUTS
}

\author{
R. D. Spence \\ S. C. Osborne
}

\begin{abstract}
A literature review was conducted on the stabilization/solidification of volatile organic compounds (VOCs). Based on this literature, it is likely that the limestone-containing grout will not permanently immobilize VOCs and that no presently available additives can guarantee permanent immobilization. The Westinghouse Hanford Company grout may be fairly effective at retarding aqueous leaching of VOCs, and commercial additives can improve this performance. Significant VOC losses do occur during stabilization/solidification, and the high temperatures of the Westinghouse Hanford Company waste and grout should exacerbate this problem. In fact, these high temperatures raise doubts about the presence of VOCs in the double-shell tanks supernates.
\end{abstract}

\section{INTRODUCTION}

Stabilization/solidification (S/S) technology is one of the most widely used techniques for the treatment and ultimate disposal of both radioactive and chemically hazardous wastes. Cement-based products, commonly referred to as grouts, are the predominant materials of choice because of their low processing costs, compatibility with a wide variety of disposal scenarios, and ability to meet stringent processing and performance requirements.

Such technology is being utilized in a grout treatment facility (GTF) by the Westinghouse Hanford Company (WHC) for the disposal of various wastes located on the Hanford Reservation, including 106-AN wastes. This document reports the results of the literature review on organic immobilization in grouts by the Oak Ridge National Laboratory (ORNL) in support of the WHC Grout Technology Program.

\section{BACKGROUND}

A grout waste form is generated in the WHC GTF. In this facility, a dry-solids blend is combined with the radioactive supernate, a low-level-liquid radioactive waste from the double-shell tanks (DSTs), in equipment located adjacent to the DSTs. (Only the solids in the DSTs are considered transuranic or high-level waste.) The resulting fresh grout is then pumped to a permanent disposal site where it forms and hardens inside an engineered barrier protecting against the intrusion of groundwater and the subsequent release of the waste constituents of concern. The grout must meet stringent process and product performance criteria dictated by the difficulties of formulating a mix to meet the regulatory and processing requirements. Once an acceptable formulation is achieved, the processing can be addressed more realistically.

As of September 25, 1990, the Environmental Protection Agency (EPA) replaced the EP.Toxicity Procedure with the Toxicity Churacteristic Leaching Procedure (TCL.P) for determining whether a waste whose status is unknown is characteristically hazardous. This new procedure 
changed the status of many wastes throughout the United States from "not characteristically hazardous" to "characteristically hazardous." The main reason this procedure changed the status of many wastes was the addition of several organic compounds to the eight metals and six pesticides/herbicides regulated under the EP-Toxicity test. There was also concern that the potential presence of organics might make the Hanford grouts subject to the land-ban restrictions. WHC was concerned that the DST supernate was potentially characteristically hazardous by TCL.P definition because of the suspected presence of the following organics: acetone, methyl ethyl ketone, methyl isobutyl ketone, and 1,1,1-trichloroethane (TCEt).

These four organics are defined as volatile organic compounds (VOCs) by EPA. (The TCLP lists extractant concentration limits for a large number of organics not regulated by the E.P.Toxicity procedure, and the limits for these four are nonlisted, $7.2 \mathrm{mg} / \mathrm{L}$, nonlisted, and $30 \mathrm{mg} / \mathrm{L}$, respectively. All four compounds are targeted for treatment under the land-ban restrictions and within the waste codes by the best demonstrated available technology (BDAT). The BDAT reference numbers are 222 , 34, 229, and 45, respectively.') Even if the supernate were not characteristically hazardous by TCLP definition, WHC was concerned that the regulators of EPA and the state of Washington might still require proof of the organic retention capabilities of the grout and engineered barriers because of the potential presence of these organics. The purpose of this project was to review the literature on the effectiveness of grouts in retaining organics and make recommendations to WHC, based on this review, about WHC formulation modifications or additives to improve the organic retention capabilities of the WHC grouts. The high vapor pressures of these organic compounds at the temperatures of these supernates, the activity coefficients of the organics (especially the hydrophobic organics), and the length of time these wastes have been stored leads one to suspect that little if any of these compounds presently remains in the DST supernate. Only the precipitates and solids present in the DST waste provide a potential mechanism for significant retention of the VOCs in the solution. However, measuring organic concentrations at the levels required by TCLP is difficult for fairly clean water and much more difficult for the chemically and radiologically harsh DST supernate. At the time this report was written, the DST supernates had not been analyzed for these VOCs; it may not be possible to measure these wasies with the accuracy necessary to satisfy regulatory concerns. This project was constrained from estimating the potential for VOC retention in the DST supernates, and organic analysis was also beyond the scope of this project. We understand that such an estimation and analysis effort is being pursued by others at WHC and Battelle Pacific Northwest Laboratories. The focus of this project was to evaluate the organic retention capabilities of grouts, not whether such organics will actually be in the WHC grouts.

\section{OBJECTIVES AND CONSTRAINTS}

The objectives of this project were (1) to conduct a computer literature search on S/S of VOCs, (2) to acquire as many of the relevant references as possible within the time schedule of the project, (3) to review these references, and (4) to make recommendations on retaining VOCs in grouts. The time period of this review covers at least 1972 through 1990. This project was constrained from estimating whether significant levels of VOCs might be present in the DST supernate.

\section{LITERATURE SEARCH}

The references listed in Sect. 8 were obtained from (1) a DIALOG ${ }^{k}$ computer search, (2) a recent literature review, and (3) references compiled during a previous project at ORNL. Appendix $A$ lists the relevant output from the computer search. The list of literature includes three previous literature reviews related to the topic of discussion: (1) a recent review concentrated mainly on post-1985 literature on the effectiveness of $S / S$ of hazardous organic waste (18 references), (2) a review up to 1985 on the $S / S$ of organic liquid wastes and sludges (125 references), and (3) a review 
done in 1985 of clay-aromatic interactions with a view to their use in hazardous waste (76 references). ${ }^{2+1142}$ Reference 2 was the review used to help compile the references listed in Sect. 8; and the references from this review, but not from the other two reviews, were included because this review has not been published yet (i.e., the references, not listed by the other two sources for this report's references, were listed to guarantee that WHC had knowledge of all the potential references).

\section{DISCUSSION OF THE LITERATURE}

With the three previous reviews and the advantage of a previous project on this subject, the literature search and list of literature (the 47 references in Sect. 8, plus those in the reviews) were fairly complete, although there is never a guarantee that every possible reference has been found. Unfortunately, only 14 of these references were in hand in time for review for this report (refis. 2.7. $8,10,12,13,15,21,22,31,32,33,42,44$, and 47). The text of the newsletter articles was included in the computer search printout and thus was available; although these articles contained some interesting qualitative information, there was little technical content that could be used to give quantitative recommendations (refs. 34 40). At the time this report was written, only an abstract, sometimes only the title and authors, was available for the remainder of the references in Sect. 8 (refs. $1,3,46,9,11,14,1620,23,30,41$, and 43,46 ). The literature review of reference 2 did give more information on its references, which are included in Sect. 8 (rets. $1,46,12$ 14, 16 18, 20, 23, $2728,31,41$, and 45 46). Thus, this report cannot be considered a complete or thorough review of the literature available for this topic. A fair job was done by using the two reviews (refs. 2 and 42 ) and the other literature in hand.

\section{I PREVIOUS LITERATURE REVIEWS}

The following two quotations from Tittlebaum et al. summarize their conclusions about the $S / S$ of organic liquid wastes and sludges before 1985 .

1. Few adequately documented studies have been reported on the performance (physical and chemical stability) of solidified and/or stabilized mixtures containing hazardous organic wastes."

2. Almost no published information exists on the nature, strength, and permanence of the bonds formed in the solidifioation and/or stabilization process. ${ }^{41}$

The Warren et al. review about organic interactions with clays covering the same time period (i.e., pre-1985) is not nearly so negative, as the following quoted conclusion demonstrates:

"However, the use of these minerals as an additive to a cementitious system would seem to offer a promising method of dealing with organic waste material and might cause an accelerated degradation of the waste." $"$ ?

This positive assessment did not conclusively address all of the concerns expressed about effective practical use of clays in $\mathrm{S} / \mathrm{S}$ of organics. The Warren et al. review acknowledges (1) that a given clay will not work for all organics, and a combination of clays will likely be needed for the variable combination of organics found in wastes and (2) that such an application still requires research and development and is not a mature technology yet. 
The more racent review of Brown et al., on the effectiveness of $\mathbf{S} / \mathrm{S}$ of hazardous organic wastes, is even more negative than that of Tittlebaum et al., as evidenced by the following quoted conclusions:

1. Therefore, the use of $\mathrm{S} / \mathrm{S}$ of organic wastes at TSD (treatment, storage, and disposal) facilities may not be appropriate because there are other treatment options which will destroy ORGANICS and eliminate any concern about the return of the ORGANICS to the environment after treatment.

2. Concerns regarding the conflict between goals for minimization of waste volumes and the inherent increase in waste volumes associated with $S / S$ of WASTES still remain. ${ }^{2}$

Conclusion number one implies that the objective of a hazardous waste treatment, storage, and disposal facility should be destruction of organics, not retention.

Brown et al. provides an excellent review of the literature on this topic since 1985 and defers to Tittlebaum et al. for the pre-1985 period. However, the authors not only cite the literature and its results and conclusions, but also draw their own conclusions, sometimes unjustifiably by unwarranted extrapolation of referenced experimental work. Sometimes, such extrapolations from two unrelated papers are used together to support the authors' contentions. Basically, the authors have adopted the regulatory perspective that the destruction of the organics is the only acceptable treatment alternative and that $\mathrm{S} / \mathrm{S}$ has not been conclusively proven to destroy the organics. Indeed, $\mathrm{S} / \mathrm{S}$ has not been demonstrated to destroy the organics in the manner of incineration, but the review acknowledges some evidence for alteration and/or bonding of organics to clays or waste form matrices. The review makes valid and thoughtful arguments from this perspective but sometimes goes too far in its desire to discredit S/S. For example, some of the more extreme arguments could be interpreted to mean that one molecule of organic would be unacceptable, because if it combined with just one molecule of water, then the concentration would exceed regulatory limits.

Brown et al. raise a valid point that the use of $\mathbf{S} / \mathrm{S}$ for wastes contaminated with organics depends on regulatory, political, and legal arguments, as well as technical arguments. They recognize the usefulness of $S / S$ for remediation of Superfund sites but question the validity of $S / S$ for such wastes under Resource Conservation and Recovery Act (RCRA) and the land-ban restrictions (i.e., $\mathrm{S} / \mathrm{S}$ is a valuable tool to remedy past mistakes but not to dispose of wastes currently being generated). (The WHC DST supernate likely falls in the latter category despite having been generated years ago, because the former category implies a waste dispersed in the environment and not easily retrieved.) They make this point in the following two sentences:

For those WASTES which are land banned because of the ORGANICS concentration, the rules do not require that the BDAT be used for processing WASTES, however, the ORGANICS content of treatment residues cannot exceed those obtained using BDAT. In contrast, the objective of an S/S treatment is to bind ORGANICS in a manner which would restrict their release to the environment, but it is not generally expected to reduce the concentration of ORGANICS in waste residues other than by dilution or by the possible loss of ORGANIC vapors into the air during the treatment.?

In summary, the key questions are (1) whether current regulatory interpretations allow the organics to remain in the treated waste, (2) what total concentration is allowed, (3) what the regulatory methods are for measuring the total concentration, (4) whether advancements in S/S of organics results in degradation of the organics, (5) whether the degradation products are environmentally acceptable, (6) whether TCl.P can be used as the means of judging S/S treatment as 
opposed to total concentration, and (7) whether the conflict between waste volume minimization and the typical volume increase experienced in $\mathrm{S} / \mathrm{S}$ can be resolved.

\subsection{FIELd APPLICATIONS}

S/S of wastes containing organics is not universally accepted in the regulatory commurity, but it has been used in remediation frequently throughout the country (refs. 8 11, 14 15, 17, 21 -27, 34 37, 39, and 44). The Office of Technology Assessment (OTA) Report Brief had the following two negative conclusions about the implementation of the Superfund Amendments and Reauthorization Act (SARA) of 1986: (1) the Superfund program does not consistently select the permanently effective treatment technologies that are preferred by SARA and (2) future cleanups are likely because of the frequent use of the impermanent technologies, land disposal and containment. ${ }^{22}$ The tone of this brief was weighted heavily in favor of incineration of organic wastes for Superfund sites over other technologies, including $\mathbf{S} / \mathbf{S}$, although no discussion was presented about whether environmental protection resulted if organic concentrations were low and little or no volume reduction resulted from incineration. The brief presents ten case studies of the selection of remedia! actions at Superfund sites, four of which used $\mathbf{S} / \mathbf{S}$ of organics as part of the selected remedial action (Chemical Control Corp., Elizabeth. N.J.; Pristine, Inc., Reading, Ohio; Sand Springs Petrochemical Complex, Tulsa County, Okla.; and Tacoma Tar Pits, Tacoma, Wash.), including one that was in situ vitrification (Pristine, Inc.).

The list of references includes two records of decision (RODs), for Velsicol Chemical Corp. III., and Commencement Bay/Near Shore, Wash., that selected S/S as part of the remedial action treatment of wastes that contained organics, including VOCs. ${ }^{910}$ The Velsicol ROD used chemical stabilization as part of the selected remedial action, but the ROD did not give details (e,g., what the reagents would be, how much would be needed) of the chemical stabilization, although estimates had been made of the effect on mobility and costs. Such details may have been given in the feasibility study that preceded the ROD and selected the remedial action from among the alternatives. This ROD did claim demonstrated effectiveness for chemical stabilization in the following quotation:

Chemical stabilization has been demonstrated to provide significant treatment benefits through immobilization of site-specific contaminants. Although not equivalent to the destruction of wastes using incineration, with proper management of residuals, stabilization technology is considered effective and less costly, and is consistent with management requirements for the existing 5/6 Pond."

The Commencement Bay ROD used polymer cement stabilization as part of the selected remedial action. The polymers were identified as silicate polymers, but it is not clear what was meant (pozzolanic reactions, proprietary silicate reactions, combination of cement and solution grouts such as sodium silicate, etc.)."

Other sites that intend to use or have used $\mathrm{S} / \mathrm{S}$ for wastes contaminated with organics include Pepper's Steel and Alloys, Burnt Fly Bog, ARCO Sand Springs, Michigan Liquid Disposal, and Saco (refs. 11,3436 , and 39 ).

Also, some laboratory studies and field demonstrations have been done on the effectiveness of $\mathrm{S} / \mathrm{S}$ of wastes containing organics. The Hazcon process was tested in the laboratory by the Waterways lixperiment Station for use at the Rocky Mountain Arsenal in Denver, Colo., and tested in a field demonstration at Douglassville, Penn., by the Superfund Innovative Technology Evaluation (SITE) program (refs. $21,2426,37$, and 40). Apparently, the initial reaction from Douglassville was positive in that a high concentration of organics was successfully solidified into a fairly strong monolithic waste form, but later results concluded that the organics were only encapsulated and not stabilized; that is, the organics were desorbed or leached relatively easily, and eventually $100 \%$ would be released to the environment. The results were similar for the Waterways Experiment Station 
laboratory study. It appears that the Hazcon reagent is useful for overcoming the interference of some organics in the setting of cement, but it does not necessarily help greatly in retaining the organics. This seems logical because the Hazcon process was originally developed to help solidify oily sludge ponds and drilling muds from oil well drilling. These wastes were difficult to solidify hecause of the high organic content, but they are not subject to environmental regulations for at least not to RCRA. Comprehensive Environmental Compensation, Response, and liability Act (CIRCLA), and SARA). It may be that this product was not previously subjected to leach testing because of this special exemption. despite the vendor claim to Waterways Experiment Station of effective stabilization against aqueous leaching; but this project has no proof of such claims one way or the other.

Another SITE denonstration evaluated the effectiveness of the Solidtech process in stabilizing wastes containing organics from the Imperial Oil Co./Champion (hemicals Superfund site. 14.1 This evaluation observed high physical stability and negligible leaching of organies (including VOCs) and concluded that the Solidtech process effectively stabilized the contaminants in this demonstration. Brown et al. do not find the evidence for organic immobilization, especially for VOCs, conclusive :

The SITE demonstration at Hialeah. Florida, was intended mainly as a demonstration of in situ $S / S$, but it used the International Waste Technology process with wastes containing organics. "A copy of this reference was not in hand for this review, but Brown et al. provide some insight into the demonstration." Once again, effective reduction of leaching organics (including $V\left(X C^{2}\right.$ ) was observed. implying that the vendor and he SITE program may have concluded that organics were effectively stabilized, but Brown et al. do not find the results to be conclusive.

Brown et al. usually cite the following two reasons for inconclusive results when negligible organics leached from the products: (1) organic concentrations were too low to be conclusive, and (2) there was no proper accounting for evaporation to know how much of the organics was in the product and how much had evaporaled." These criticisms are valid, especially for the lield demonstrations. In general, studies have been conducted as treatability studies, where the existing concentrations in the waste were not boosted by spiking, even if low, and evaporative losses during treatment were not monitored. Current organic analytical techniques are quite sensitive to the presence of a given compound, but quantitation can be quite inaccurate, especially for soils and sludges. (It is acknowledged that evaporation is allowable, even desirable, but it is maintained that reproducible and predictable evaporation during $S / S$ has not heen demonstrated and that "permanent" immobilization of organics has not been demonstrated.) Spence el al. specifically designed their laboratory study to overcome these two limitations in evaluating the effectiveness of four vendor formulations in immobilizing eight VOCs. ${ }^{13}$

Although the sludge from a Superfund site provided the basic matrix for the study, Spence et al. spiked this sludge with enough of the eight VOCs to guarantee measurable concentrations in the leachates, and the amount of VOCs that evaporated during mixing with the vendor reagents and during curing was measured ${ }^{12.11}$ Thus, mass-transfer parameters and the fractions evaporated during preparation were estimated. Not surprisingly, the different reagents had varying degrees of success with the different compounds; that is, a given reagent might be more successfiul than another for one compound but less successful for another compound. Also, not surprisingly, the hydrophilic compounds proved to be the ones least immobilized during aqueous leaching. It was concluded that signiticant amounts of VOCs would be retained during $S / S$ treatment, that $S / S$ was only moderately successful in immobilizing VOCs, that $S S$ was a viable remedial action candidate for the target waste (sludge heavily contaminated with metals but only slightly contaminated with VOCs), and that $S S$ was not suitable for high organic concentrations (individual VOC concentrations above $0.01 \mathrm{wt} \%$ appear treatable, but not necessarily those as high as $0.1 \mathrm{wt} \%$ ). (Higher concentrations of heavier, less mobile semivolatile species appear treatable, probably because of their hydrophobic nature and affinity for solid surfaces.)

The IPA review of mobile technologies for Superfund wastes asserts that $S / S$ is well suited for treating sludges and soils containing up to $20 \mathrm{vol} \%$ organics and that some vendors can handle up to $100 \%$ organics, although a more typical maximum is 20 to $40 \%$." Webster indicates that one benefit of $S / S$ is encapsulation of wastes in a low permenbility product but that organophilic agents can help 
stabilize organics when high concentrations $(>30 \%)$ are mingled with inorganic wastes. ${ }^{44}$ Alternatively, incineration, biological treatment, or recovery processes can be employed in conjunction with stabilization to remove the organics before $S / S$ of the inorganic portion. ${ }^{44}$

\subsection{ORGANIC LOSSES DURING GROUT FORMATION}

Two studies measured losses during implementation of $\mathrm{S} / \mathrm{S}$; both were laboratory studies (refs. 7, 32, 33, 38, 45, and 46). The objectives of the two studies were different. The studies conducted by Weitzman in collaboration with various colleagues were intended to measure the level of VOC evaporation during mixing of the waste with $\mathrm{S} / \mathrm{S}$ reagents and during the cure of the product. Spence et al. were measuring the immobilization, or leachability, of VOCs and the amount that evaporated during leach sample preparation and curing in order to estimate the VOCs retained, stabilized, or immobilized in the sample prior to leaching.

The Weitzman study used a synthetic waste matrix of soil and water. ${ }^{7}$ Latex paint sludge was part of the waste matrix in some tests to evaluate the effect the presence of organic solids would have. The waste matrix was added to a 5-gal pail, followed by water, the VOC spike, and stabilizer (50\% fly ash and $50 \%$ Portland cement or lime kiln dust, no special reagents such as organophilic clay for organic stabilization). The pail was placed in a Lundberg mixer, the mixer was mounted in a wind tunnel, the mixer was turned on, and mixing continued for 60 to $90 \mathrm{~min}$. After the mixing, the pail was removed and sealed with its lid, and then air was pulled through the pail headspace at a controlled rate for 30 days. The wind-tunnel gas flowrate and VOC concentration were monitored continuously during mixing, and the VOC emissions from the pail were measured for 3 or $4 \mathrm{~h}$ every 3 or 4 days. These details are important because it is not surprising that 80 to $40 \%$ of the VOCs was lost following these procedures. ${ }^{2}$ This procedure did not thoroughly mix the VOCs into the synthetic waste solids before the stabilizer is added. In other words, the VOC compounds were left on top without being mixed into either the surrogate soil or a cementitious waste form. Also, vendors do not use a cement-fly ash or lime-fly ash formulation alone to stabilize organics. These ingredients are used as the main binding constituents of most $\mathrm{S} / \mathrm{S}$ formulations.

Spence et al. had considerable difficulty trying to mix a VOC spike into a sludge sample prior to stabilizing, using a procedure similar to the previous one. ${ }^{12,33}$ About $90 \%$ of the VOCs dumped on the sludge was lost during mixing of the spike into the sludge. For this reason, the sludge was sampled before stabilization inside a glovebox. The VOC content of the sludge samples was measured and used as the sludge VOC content before stabilization. The sludge was spiked inside a hood, sampled, transferred to a glovebox, mixed with vendor reagents designed for organic retention, packed in molds, sealed inside a pipe with little headspace, and cured for 28 days. The VOC

concentration of the glovebox air was measured after the samples were sealed inside the pipe, and the VOC concentration of the pipe air was measured prior to opening the pipe, removing the samples, and starting aqueous leaching inside zero-headspace extraction vessels. These two VOC concentrations measured in air were used to estimate the amount of VOCs evaporated during sample preparation and the amount retained in the samples prior to leaching. In general, less than $50 \%$ of the VOCs in the sludge after spiking was evaporated during mixing and curing. (The amount evaporated during the 28 days of curing was negligible compared to that evaporated during mixing, because the headspace of the pipe was practically negligible.)

Both of these laboratory studies were conducted at room temperature, with the understanding that the exothermic hydration reactions were free to proceed and the resulting mixes free to come to thermal equilibrium with their surroundings. The resulting temperatures would be far lower than that expected for the Hanford grouts. Consequently, one would expect higher VOC losses during mixing of the Hanford grouts under the same conditions (except temperature) than from either of these two studies. These two studies were not consistent (one showing losses during mixing of $>90 \%$ and the other $<50 \%$ ) because of differences in apparatus and procedures. The Weitzman study dumped the VOCs as a concentrated spike on top of the surrogate waste with no mechanical mixing, a procedure 
guaranteed to evaporate a volatile material. Spence et al. dispersed the VOCs in the sludge matrix before mixing it with $\mathrm{S} / \mathrm{S}$ reagents and measuring losses.

Neith r laboratory study was a scaled representation of the mixing and VOCs loss that would be expected from a field $\mathrm{S} / \mathrm{S}$. The Weitzman mixing may have been more representative of excavation and mixing, and the Spence mixing more representative of in situ S/S. Basically, these results were qualitative estimates of losses during field $\mathrm{S} / \mathrm{S}$ at best. The Weitzman studies hint, but do not definitively establish, that mass transfer of VOCs via the gas phase may be equal to or greater than the transfer via the aqueous phase. This possibility is not surprising considering the high volatility and hydrophobic nature of some of these compounds. Some regulatory positions imply that losses to the air are allowed and are desired over losses to groundwater and aquifers.

\subsection{BASIC STUDIES OF ORGANIC IMMOBILIZATION}

Permanent bonding and degradation of organics with clays and modified clays have been reported (refs. 2, 12-13,29--31, and 42). Apparently, the affinity of organics, particularly pesticides/herbicides, for clays has been well known for some time. ${ }^{42}$ The interlamellar areas of the clays adsorb organic molecules, catalyze free radical oxidation of these molecules (degradation), and stabilize the reaction products. Hydration of the clay adversely affects these beneficial effects; the bonding of the active sites with water apparently is stronger than the adsorptive bonding with the organics. The interlamellar cations bonding the clay layers apparently catalyze ligand-forming reactions, and the polymers formed adsorb on the clay surface (dimers, irimers, and tetramers are the polymers referred to). Substituting quaternary ammonium compounds for these cations (forming organophilic clays) made the local environment more conducive to organic molecules and organic adsorption in an aqueous environment. The following abstract summarizes the interaction of organics with clays:

This paper reviews the history of clay-aromatic interactions particularly in the areas of the "benzidine-blue" reaction; pesticides and benzene and its derivatives with a view to the use of clay minerals as an additive to cementitious materials in order to bind organic compounds in hazardous and toxic wastes. It is concluded that these minerals can act as catalysts in a free radical oxidation and that absorption onto the clay surface accelerates the reaction and stabilizes products. The extent of hydration of the clay affects the strength of the acid sites on the clay surface which in turn can affect adsorption. Adsorption and reactions are also dependent on the ligand-forming properties of the exchangeable cations in the clay as well as the extent to which they cause the clay layers to expand, transition metals and quaternary ammonium cations being more reactive than alkali and alkali earth cations. ${ }^{42}$

Despite this evidence of organic interaction with clays, there was no strong or irrefutable evidence of immobilization of organics after $\mathrm{S} / \mathrm{S} .{ }^{2,41}$ There is apparently a gap between the scientific understanding of the interactions that do occur between organics and clays and the application of this knowledge to treatment of hazardous and toxir urganic wastes. It is possible, in some cases, that the technology is being misapplied (e.g., wrong clays, incorrect modification, wrong organic compounds for clay interactions, too little clay or too much organic). It is important to note that not all of the proprietary treatments use clays. Some S/S treatments (meaning additives used as part of the solidification reagents, and not some pretreatment separate from S/S such as incineration or extraction) may depend on physical encapsulation, and others that do not use clays may rely on degradation. Most of the open literature involves clays, leading to the focus on clays of this report.

Part of the problem in application may be regulatory and political, not technical. For example, $\mathrm{S} / \mathrm{S}$ may be accepted for a Superfund site if treatability studies clearly demonstrate treatment goals can be achieved. But acceptance may not be automatic for RCRA or land-banned wastes, even if S/S 
achieves BDAT performance. The reason is regulatory and political interpretation of the relevant laws and regulations. Basically, a proposed treatment must meet or exceed BDAT performance. BDA'T performance is measured either by total analysis for the contaminant before and after treatment or TCLP testing before and after treatment (the regulatory community is divided on these issues). The regulatory community is well aware that an $\mathrm{S} / \mathrm{S}$ treatment might mask the analysis of compounds still present or that evaporation of VOCs might occur during treatment. The BDAT for organics is incineration, and some in the regulatory community will accept nothing less than clear and unequivocal proof of conversion of organics into "innocuous" components (carbon dioxide and water). This is an oversimplified but fairly accurate statement of the most extreme position. The OTA Report Brief takes this position without actually stating it. Its position is that if organics are present, then incineration should be the treatment of record. Other treatments can be considered as long as the result is the same, for example, chemical oxidation or destruction in aqueous systems or extraction with later destruction or recycling of the extracted organics. This is a reasonable position defined by the relevant laws. The intent of the land-ban restrictions is that none of these organic compounds will be landfilled where they might be released into the environment later. The OTA Report Brief takes that position with respect to Superfund sites where regulators more readily accept S/S (depending upon the area of the country and the regulator). The UTA Report Brief position, while more or less correct for RCRA or land-banned wastes, is extreme for Superfund sites because contamination often is dilute and dispersed widely in the soil and groundwater. RCRA wastes are currently being generated, the quantities are at a minimum and the concentrations at a maximum, and the waste can be treated by incineration or its equivalent to remove or reduce the organics prior to disposal. CERCLA and SARA wastes might involve volumes that are orders of magnitude higher and concentrations that are orders of magnitude lower than the original waste. It may be more ecologically and environmentally destructive to dig up an entire region in order to incinerate every particle of soil contaminated with trace quantities of organics than to do nothing. That is the reason innovative technologies such as in situ $\mathrm{S} / \mathrm{S}$, in situ extraction, and in situ bioremediation are being studied by EPA and others.

Recent evidence appears to demonstrate permanent bonding of organics with S/S additives (refs. $12-13$ and 29-31). Brown et al. thought those laboratory results might be misleading as to the $\mathrm{S} / \mathrm{S}$ of actual wastes, because the observed bonding occurred for the organic compound in isolation with the organophilic clay (i.e., dry and not in the presence of the binder reagents and other "nasty" wastes). ${ }^{2}$ The effect of aqueous systems on these interactions has already been mentioned, although the modification to an organophile counteracts these effects to some extent. Brown et al. contend that the main observed interaction was reversible adsorption, meaning that these compounds will eventually be released into the environment and that the effect of $S / S$ will be to dilute and delay this release. Much of the reported empirical evidence on S/S supports this contention. It is pointed out that the concentration of organic relative to the additive (or modified clay) might account for part of the difference. For example, the concentration used by Soundararajan in his studies was orders of magnitude below that claimed to be effective by proponents of $S / S$. It is possible that very little organic actually degrades or bonds per unit weight of clay and that the organic that reacts is only a fraction of the organic needed to force access to the active sites. Such possibilities give rise to competing desires. It is desirable to bond the organic permanently, but if the active sites can only bond a tiny fraction of the molecules present, it may be more desirable to have catalysis of degradation and release of the degradation products (if they are innocuous) so that the reacting continues. The literature hints that degradation is catalyzed, but that the reaction products collect on the clay surface, potentially blocking the catalysis sites. It appears clear that permanent bonding and degradation occurs; it is not clear how much clay or time is required per unit of organic to permanently bond or degrade most of a given amount of organic. The available literature seems to indicate that permanent bonding and degradation occurs, but not for a significant amount of the organics treated. Most of the organics are reversibly adsorbed, and the beneficial effect of $S / S$ is 10 attenuate the release rate. The waste forms may be designed so that the release rates are small enough to allow dilution and biodegradation to innocuous concentrations. None of this is known 
conclusively, and improvements may be made to the reagents. More basic studies are needed on the bonding and degradation capabilities and limitations of modified clays outside the complicated environment of wastes and $\mathrm{S} / \mathrm{S}$ before such permanent immobilization of organics can be claimed for $\mathbf{S} / \mathbf{S}$. It is established that these additives interact with organics and can help retain organics during aqueous leaching (i.e., the mass transfer resistance of the waste forms is improved).

\section{SUMMARY AND CONCLUSIONS}

\subsection{IMPACT ON WESTINGHOUSE HANFORD COMPANY}

The impact of organics in Hanford supernates on the WHC grout program depends on two different perspectives: (1) regulatory interpretation and approval and (2) technical performance. Regulatory interpretation and approval is beyond the scope of this project and rcport, but WHC needs to investigate what the regional and local regulatory position will be if these supernates prove to contain hazardous organics. Previoi's interpretations imply that removal of the organics may be required prior to $\mathrm{S} / \mathrm{S}$. Processes are available for doing this, but further development of the processes will be required for application to these difficult and chemically harsh DST wastes. The more innovative processes (e.g., chemical oxidation and sorptive separation) may be difficult to implement. (An innovative technique of $A$. J. Mattus of ORNL offers the hope of destroying both organics and nitrates in these aqueous solutions, but it is an unproven technology and may take years of development.)

The simplest approach may be the best. In the unlikely event that these VOCs do prove to be present and the regulators require their removal, air stripping may remove the VOCs still present after all these years at the temperatures of the DST waste. VOCs held in the solids might buffer the solution VOCs and requir: long stripping times. If this is unacceptable, the supernate can be separated from the solids, as was intended for $\mathrm{S} / \mathrm{S}$, and stripping performed on the supernate alone. This may tequire the construction of a stripping unit in addition to the GTF already in place if facilities are not available to accomplish the stripping. Negotiations with regulators will establish the level of treatment required of the air from the stripping process prior to its release (the radioactivity will undoubtedly necessitate passing the air through a high-efficiency particulate air filter prior to discharge and the potential VOCs may require passing the air through an activated charcoal bed or similar treatment).

This project was constrained to assessing the effectiveness of the Hanford grout disposal in retarding VOCs release and assessing what, if any, additives might improve performance, based on the literature review, rather than assessing the suggested pretreatments. The DST wastes, Hanford grouts, and Hanford grout disposal present several inportant differences from the $S / S$ of hazardous and toxic wastes discussed in the literature:

1. Most obvious, but not so important in this discussion, is the radioactivity of the waste. The radioactivity dictated the need for minimizing exposure of personnel, the design of the GTF and grout, and the design of the multi-barrier disposal, making it important from those aspects.

2. The grout is quite soupy, unlike the thick grouts generated in $S / S$ of soils. The excess water creates a weaker product and more mass transfer pathways.

3. Perhaps most important is the high temperature of the waste and grouts. These temperatures make it less likely that even the hydrophilic ketones will be in the waste or will be retained in the grouts. Also, these temperatures will form different chemical and morphological waste form matrices than those usually formed in $\mathrm{S} / \mathrm{S}$. The effect of this structural difference on VOC retention is unknown. The higher temperatures likely will adversely affect $V O C$ adsorption, although degradation reaction rates may increase. 
4. The engineered barriers for the Hanford multi-barrier design are better and more extensive than those in most remedial actions using S/S. Usually a RCRA cap and sometimes a lined landfill is used, but not grout inside a concrete container and surrounded by gravel and asphalt vapor barriers. The Hanford grout was not designed as the primary leaching barrier. The design prevents water access to the grout far better than many $S / S$ remedial actions in which soil is treated and placed back in the same location, even if RCRA caps are used. It is far more likely that this separation from a wet environment, combined with the high temperatures, will lead to evaporation of VOCs and vapor phase transport.

The criterion for leachability is a leachability index of 6.0 or better. The leachability index for the mobile nitrate ion was surprisingly high for the limestone grouts (around 8.0) and perhaps can be attributed to the use of granulated blast furnace slag, an excellent leach-resistant component. The leachability index for the VOCs would be expected to be about the same as that of the nitrate using this grout, because nitrate leachability is considered to be a measure of the physical barrier to leaching. Organophilic clays or proprietary reagents for organic retention would be expected to improve the VOC leachability index of this limestone grout moderately. Based on the nitrate leachability index, the VOC leachability index of the 106.AN grout would be expected to exceed 8.0. Based on the past performance of commercially available products, a given additive could be expected to improve one of the VOCs or a class of the VOCs, but a different additive may be required for each VOC or class to improve all of the VOCs. The expected improvement would be on the order of increusing the leachability index above 9.0 ; that is, the VOCs would still be leachable but at a slower rate. These estimates are speculation, and the leachability indices of the VOCs for these grouts should be measured.

\subsection{RECOMMENDATIONS FOR WESTINGHOUSE HANFORD COMPANY}

With regard to VOCs in the DST supernate, it is recommended that WHC:

1. Either estimate the partitioning of any VOCs between the supernate and headspace after these many years or measure whether any VOCs are really present, preferably the latter, if possible (e.g., by gas chromatography-mass spectroscopy).

2. Ascertain what the regulatory position will be if VOCs are in this waste, that is, whether $S / S$ and the planned disposal will be allowed and, if so, what the performance criteria will be (e.g., what TCLP concentration) or, if not, what level of VOC removal will be required.

3. If the desire is to avoid risks, add commercially available additives for each VOC of interest to the grout formulation. This process will likely involve two to four modified clays plus other reagents and will probably increase the cost of the grout formulation significantly. Specifically, one clay modified for organophilic compounds such as the ketones and another modified for organophobic halogenated compounds such as TCEt would be recommended. Other general organic sorbents or solvents may be incorporated into the waste form. The effectiveness of these additives for these VOCs in the surrogate wastes and in the WHC grout at the high temperatures of the materials should be demonstrated prior to acceptance. TCLP testing of the WHC grout using surrogate wastes spiked with VOCs could test the sensitivity of the WHC grout to VOC concentration and the effectiveness of additives; that is, the testing could serve as treatability studies. It appears that no treatability exclusion would be required as long as surrogate wastes are being tested. [CAUTION: The real waste could behave significantly differently from the surrogate waste.] 


\section{ACKNOWLEDGMENT}

The efforts of Ivan Morgan, Mike Gilliam, and George Kamp and the support of the Robins Air Force Base, the Hazardous Waste Remedial Actions Program of the Department of Energy, and the Waste Management Technology Center on a previous project at ORNL involving volatile organic immobilization in cementitious waste forms contributed significantly to better understanding of the role of grouts in immobilizing organics and are gratefully acknowledged. The support of Jeff Voogd. Earl McDaniel, Mike Gilliam, and WHC for this project is also gratefully acknowledged.

\section{REFERENCES}

1. S. A. Boyd, S. Shaobai, J. F. Lee, and M. M. Mortland, Clays and Cloy Mineruls, 36 (2), $125-130(1988)$.

2. R. E. Brown, B. S. Jindal, and J. D. Bulzan, "A Critical Review of the Effectiveness of Stabilization and Solidification of Hazardous Organic Wastes," presented at the Second ASTM International Symposium on Stabilization/Solidification of Hazardous, Radioactive, and Mixed Wastes, Williamsburg, Va., May 29-June 1, 1990; ASTM STP 1123, 1992.

3. R. Caldwell and P. Cote, "Investigation of Solidification for the Immobilization of Trace Organic Contaminants," ENVR 53, presented at the Third Chemical Congress of North America at the 195th American Chemical Society Meeting in Toronto, Ontario, Canada, June 5 10, 1988.

4. C. T. Chiou, L. J. Peters, and V. H. Freed, Science, 206, 831-832 (1979).

5. C. T. Chiou, P. E. Porter, and D. W. Schmedding, Environ. Sci. and Technol, 17 (4), 227-30 (1983).

6. P. R. de Percin and S. Sawyer, "SITE Demonstration of Hazcon Solidification/Stabilization Process," presented at the 14th Annual Research Symposium, Remedial Action. Treatment, and Disposal of Hazardous Waste, Cincinnati, Ohio, April 1988.

7. P. R. de Percin and L. Weitzman, "Air Emissions from Hazardous Waste Stabilization," in Proceedings of the 1988 EPA/APCA International Symposium on Measurement of Toxic and Related Air Pollutants, Research Triangle Park, N.C., May 1988, P413 (5).

8. EPA 540/2-86/003f, Mobile Treatment Technologies for Superfund Waste, pp 3-1 3-5.

9. EPA-ROD-R05-88-081, Superfund Record of Decision (EPA Region 5): Velsicol Chemical Corporation. Marshall, Illinois (First Remedial Action), September 1988.

10. EPA-ROD-R10-88-011, Superfund Record of Derision (EPA Region 10): Commencement Bay/Near Shore, WA (First Remedial Action), December 1988.

11. Florida Power \& Light Company, Fixation/Stabilization Final Report: Pepper's Steel and Allows Site, Medley, Florida, Vols. I and 2, Juno Beach, Fla., November $198 .$.

12. J. J. Gibbons and R. Soundararajan, American Lahoratory, 20 (7), 38-46 (July 1988).

13. J. J. Gibbons and R. Soundararajan, American Lahoratory, 21 (7), 7079 (July 1989).

14. W. E. Grube, Jr., "Evaluation of the Solidtech Solidification and Stabilization Technology," in Proceedings of the Third International Conference on New Frontiers in Hazardous Waste Management, September 10-13, 1989, Pittsburgh, Pa., EPA/600/9-89/072. August 1989.

15. W. E. Grube, Jr., J. Air Waste Manage, Assoc., 40 (3), 310-16 (1990).

16. J. W. Hamaker and J M. Thompson, Organic Chemicals in the Soil Environment, Marcel Dekker, Inc., New York, 1972, pp. 49-143.

17. J. G. Herrmann, The Superfund Innovative Technology Evaluation Program: Technology Profiles, EPA/540/5-88/003, November 1988.

18. M. B. McBride, T. J. Pinnavaia, and M. M. Mortland, Fate of Pollutants in the Air and Water Environments, Pt. I, John Wiley and Sons, Inc., 1977, 145 54.

19. D. Montgomery, C. J. Sollars, T. S. Sheriff, and R. Perry, Environ. Technol. Lett, 9 (12), $1403-12(1988)$. 
20. M. M. Mortland, S. Shaobai, and S. Boyd, Clans and ('/ay Minerals, 34 (5), $5815(1986)$.

21. T. E. Myers and M. E. Zappi, Lahoratory Investigation of Organic (ontaminan' Immohilizallon hy Proprietary Processing of Basin F Liquid Rocky. Mountain Arse'nal, Dener. C'olorado, Technical Report EL-87.11, Waterways Experiment Station. August 1987.

22. OTA Report Brief, "Special Report: Are We Cleaning Up" 10 Superfund Case Studies," June $i 988$.

23. G. Rowe, Evaluation of Treatment Techmologies for Listed Petroleum Refinery Waste's, Fimal Report, American Petroleum Institute, No. 4465, May 1988.

24. S. Sawyer, Applications Inalywis Report: HAZCON Solidification Process. Donglaswille, Pennsy/vania, EPA/540/AS-89/001. May 1989.

25. S. Sawyer, Techoology Evaluation Report SITE Program Demonstration Test. HATC $O N$ Solidification. Douglassville, Pennsy/vania. Volume 2, EPA/540/5-89/00IB, February 1989.

26. S. Sawyer, Technology Evaluation Report S/TE Program Demonsiration Test. H.AZC(ON Solidification, Douglassville; Pennsylvamia. Volume I, IPA/540/5-89/101A, February 1989.

27. S. Sawyer and M. Stinson, Techmology Evaluation Report SITE Program Demonsiration Test. International Waste Technologies In Situ Stabilization and Solidification. Hialeah. Filorida, EPA/540/5.89/004a, June 1989.

28. T, S. Sheriff, C. J. Sollars, D. Montgomery, and R. Perry, Environmental Technolengy Le'thers, 8, s01-14 (1987).

29. R. Soundararajan, E. F. Barth, and J. J. Gibbons, Evaluation Using an (Organophilic ('lan. 10) Chemically Stabilize Waste C'ontaining Organic Compounds, LPA/600/J-90/020. IPublished in Imernational d of dir Pollwaion Control and Hazardous Waste Management. (January liebruary 1990)].

30. R. Soundararajan and J. J. Gibbons, "Nature of Bonding Between Organic Wastes and Solidification Binders," ENVR 5l, presented at the Third Chemical Congress of North America at the 195th American (hemical Society Meeting in Toronto, Ontario, Canada, June 510.1988.

31. R. Soundararajan, E. F. Barth, and J. J. Gibbons, Hazardous Materials (ontrol, 3 (1), 42 s (January February 1990).

32. R. D. Spence, T. M. Gilliam, I, L. Morgan, and S. C. Osborne, Imimobilization of Volatile (Organic Compounds in commercial c'ement-Based Waste Forms, ORNL/IM-11251, Martin Marietta linergy Systems, Inc., Oak Ridge National Laboratory, December 1990.

33. R. D. Spence, T. M. Gilliam, I. L. Morgan, and S. C. Osborne, "Stabilization/Solidification of Waste Containing Volatile Organic Compounds in Commercial Cementitious Waste Forms," presented at the Second ASIM International Symposium on Stabilization/Solidification of Hazardous, Radioactive, and Mixed Wastes, Williamsburg, Va., May 29 June 1, 1990) (10 be published in proceedings).

34. Superfund. "Treatability studies set for Burnt Ply Rog," 2 (May 9, 1988), Pasha Publications, Inc.

35. Superfiund, "ARCO to fix Sand Springs whether hy cement or fire," 2 (June 6, 1988), Pasha Publications, Inc.

36. Superfund, "Dispute over remedy brings Mich. talks to halt," 2 (February 1988), Pasha Publications, Inc.

37. Superfiund, "IEPA finds Hazcon process organics leach," 3 (July 31, 1989), Pasha Publications, Inc.

38. Superfund, "Solidification releases VOCs," 3 (Aug. 28, 1988), Pasha Publications, Inc.

39. Superfund, "EPA wants to solidify Saco wastes," 2 (Aug. 29, 1988), Pasha Publications, Inc.

40. Superfund, "Hazcon SlTE test shows good results," 2 (June 20, 1988), Pasha Publications, Inc.

41. M. E. Tittlebaum, et al. ('RC C'ritical Reviews in Environmental comerol, 15 (2), 179211 (1985)

42. D. S. Warren, A. I. Clark, and R. Perry, The Science of the Total Einvironment, 54, 1.5772 (1986). 
43. D. M. Webster, J. Air Pollut. Comtrol Assoc, 36 (10), 115663 (1986).

44. W. C. Webster, Mazardous Materials d Waste Management Magazine, 18 '0 (May June 1987).

45. L. Weitzman, L. E. Hamel, E. F. Barth, pp. 54257 in Procesdings of the Ith Ammual Rescorch Simposium, Land Lisposad, Remedial Action, Incimeration, and Treatme'nt of Hazardous Waste: Cincinnati, Ohio, April 1988, EPA/60049.88/021.

46. L. Weitzman, L. E. Hamel, P. de Percin, and B. Blaney, pp. 448458 in Proceedings of the 15 th Annual Research Symposium. Remedial Aivi,m, Treatment, and Disposal of Hazardous Waske. Cincinnati, Ohio, April 1989, EPA/600/9.90/006.

47. J. R. Conner, Chemical Fixation and Solidification of Hazardous Wastes, Van Nostrand Reinhold, New York, 1990, 117. 
APPENDIX A: RESULTS OF THE COMPUTER IITERATURE SEARCH 

159329 WASTE
833464 FORM? ?
2074 HASTE $(W)$ FORM? ?
51 47 (VOC? ? OR VOLATILE(W)ORGANIC? ?) AND (STABILIZ? OR SOLIDIF?) AND (CEYENT? ? OR GROUT? ? OR COHCRETE? ? OR
WASTE(W) FORM? ?)

?tom 1

$\rightarrow \rightarrow$ Duplicate detection is not supported for vile 340.

$\rightarrow P 20$ ords fron unsupported $110 \mathrm{~s}$ will be retainad in the Ro set.

...completed examining records

?t $2,52,1-42$ 42 RD S1 (unlque items)

2. $3 / 1$

(tten 1 from file: 5 )

000765585 BIOSIs Nuntor: 90033192

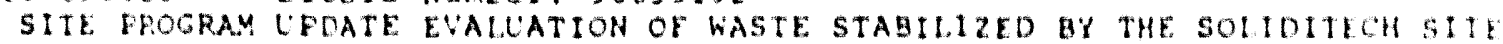
IFCH:OLOGX

GFCRE W E IR

U.S. FWVIRON, PFOT. AGENCY, CIHCINNATI, OHIO 45268, USA.

J AIR WASTE MANGE ASSOC 40'(3). 1990. 310-316. CODEN: JANAE

tanguage: ENGLISH

Sublile: BA (B.0loglcal Abstracts)

Tha sollditech technology demonstration was conducted at the Impetal 0:1

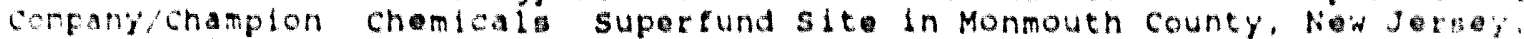
contanination at this sto includes poBs. lead (with varbous other mo: als), and oll and quage. The soliditech process mixes the wate matertal itith proprlatary additives, pozzolanlc materlals, and water, in a batch rixer. Tactnical criteris used to ovaluate it efectivenos include (1) shot torm oxtraction and anglneering tosts: (2) long-term oxtraction ats leaching tosts; (3) petrographic examination: and (4) structural integtit; starvatione. Throe difterent wase types.sbd.contaminatod soll, wasto

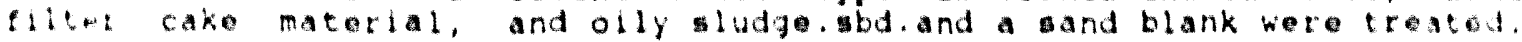
Guteon cuble yards of treated wasto monolitha, and nesrly 300 cas:

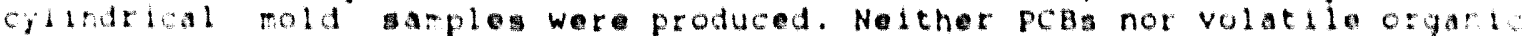
founds hete detectod in the retp extracts of trantod bistes.

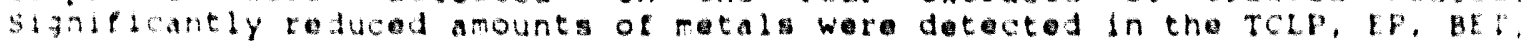
a.t Ais 15.1 extracts of trostad wates compated to untrosed. 1 . - nontations of phenols and crosols were detected in post-treatment toli

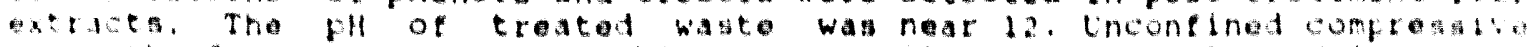
stregth of treated wastag was hlgh; permeabllity was vely low. Wolght lows

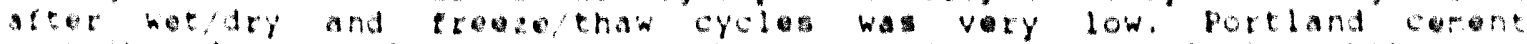
ootultutel several netals to the trated wasto physlcal abablity $\because 1: 01$ wstos was high. Data trom all axtraction and leaching tests sho.el ratibla rolease of contaminants. Phenolg and cresols apposel ta

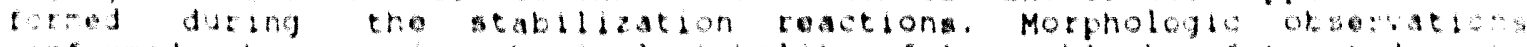

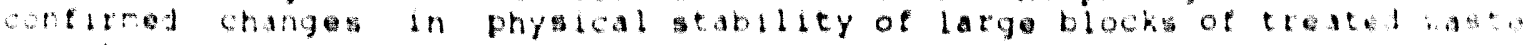
$0.0 \mathrm{tan}$.

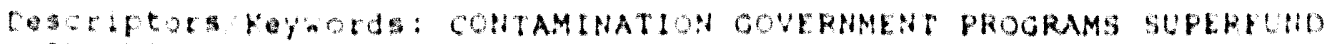

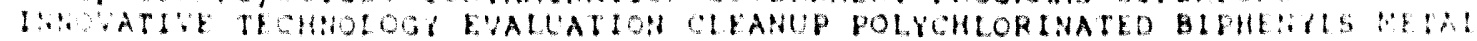

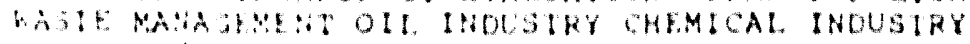

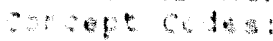

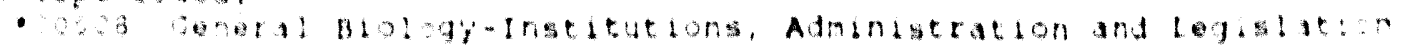

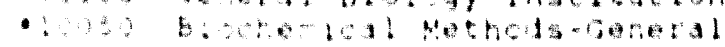

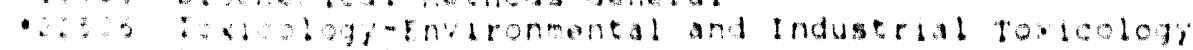

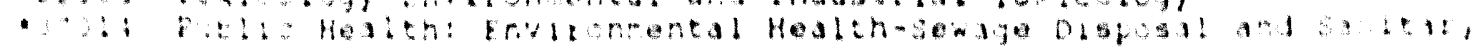

$\because+\frac{1}{20}$

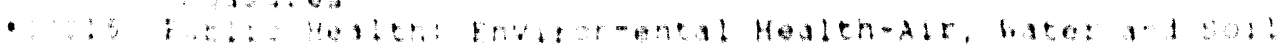

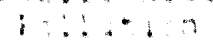


:0060 Blochemical studies-General

10069 blochemlcal studlas-Minerals

$2 / 5 / 2$ (Iten 2 from t11e: 5)

0005756322 BiOsIs Number: BJol8629

ENCEOSEO THERMAL SOIL AERATIOH FOR RLMOVAL OF VOLATILE ORCAHIC

CONTAYIRATION AT THE MCKIN SUPERFUND SITE GRAY MAINE USA

WESTER D M

L.S. EHVRONMENTAL PROTECTION AGEHCI, WASTE MANAGEMENT DIVISION, BOSTON, PASSCHUSETTS.

J AIR POLLUT CONTROL ASSOC 36 (10), 1986. 1156-1163. CODEN: JPCAA

Full journal Title: Journal of the Air pollution control Asaciation Lamgulage: FNGLISH

sublile: BA (Blologleal Abstracts)

During the winter and spring of 1986 andy ella contaminatod with volatile organle chemleals were ouccessully treatad durlnga pliot atudy of an nclosed thermal soll aration procese at the Mekin supertund ito ln Orsy, Malne. Excavated soll contalning up to 3310 ppm of trichloroethylere

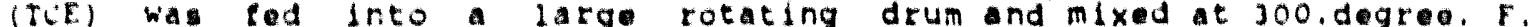
Aerated soll wan then wolldifled with cement and water and returned to the on-3 te excavation location. Exhaustad alr from the onclosed a ration proce wan treated in baghouse, a serubber, and a vapor phase catbon bed

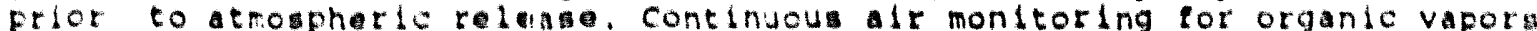
and particulater took placo at tho de perlmeter and for organle vapors at on-ite locations. Tachnigue to mininize uncontrollad volatization of organie chemleal trom tha coll during axcavation and aration and to control dust omlelons ware lmplemented. Resulta of this pliot etudy Indicat that comentratlone of volatile organle contaminantw routineli

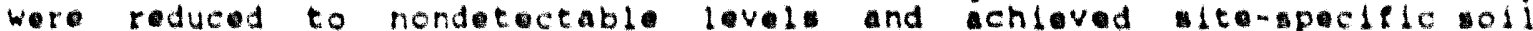
fortormance targets atablined by tha U.s. Envlronmental protection Agency. The pliot sudy wa conducted by canonie Environmental setvice corporation and lunted by privata companlan undar order from tra.

Desctptors/Keywotd : EPA VOLATILIZATION CONTROL DUST EMIS\$ION CONTROL.

TRTCHLOROETHYLEHE

Consept codes:

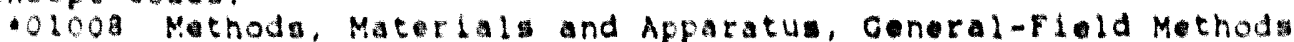

- otsol Eologyi Envitonmental Blology-Bloclimatology and Bloneteorologi

- 10050 Blochemleal Method-Ganeral

10s11 Blophy les-bloenglnouring

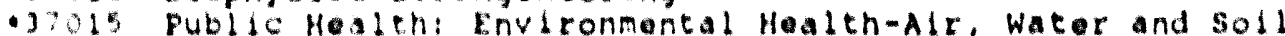

Pollution

- 2301 soll Sclenc-General: Mothods (1970=)

- 5235 soll selence-phylea and chemletry (1970-)

ops General Aiology Insticutions, Adminlatration and taglelation

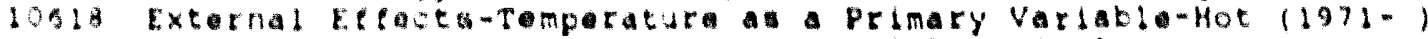

22506 Toxicolog;-Envitonmental and Induserial Toxtcology

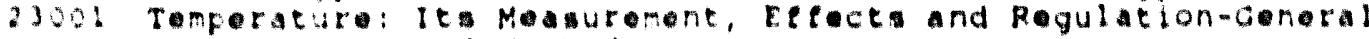
Mavurament and Methods

2.5 (Item 1 tron $110: 40)$

20524l Envitoline Nunber: bo-0027ag

AIR EYSSIOHS FROH HA ARDOLS WASTE STABILIZATION,

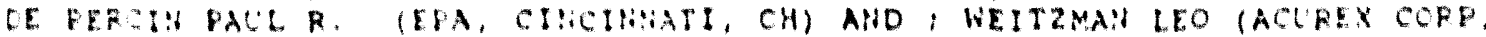
FSEAFG TRIAISLE PAPE, VE)

EFA MA MEAS:PE:DE OE TOYIC AID RELATED AIR POLLUTAITS IIIL SI:

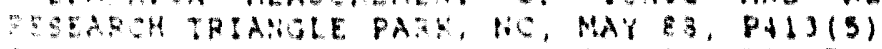

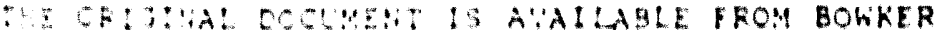

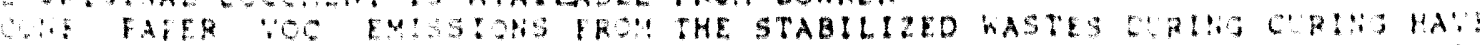
- $\because$ E 


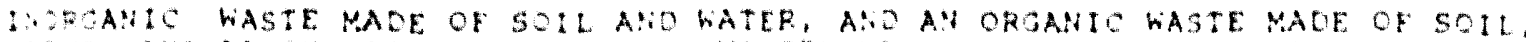
WATER, AVD LATEX PAIIT SLLDGE. THE WASTES HERE STABILIZEO WITH A MIXILRE O OI HLYASH ANO 501 PORTLAND CEMENT OR LIME KILN DUST. MEASLREMEMTS FOLIOS

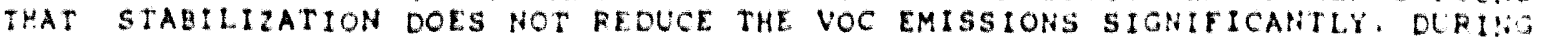
:HE STABILIZING PROCESS, EMISSIONS YROM THE WASTES WERE SIGNIFICANTLY

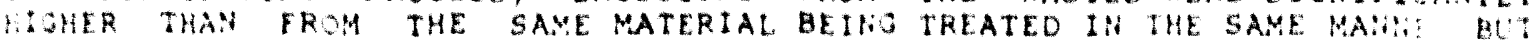
W THOLT THE AODITION OF SOLTDIFICATION AGEMTS. (L TABLE)

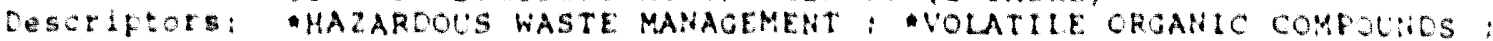

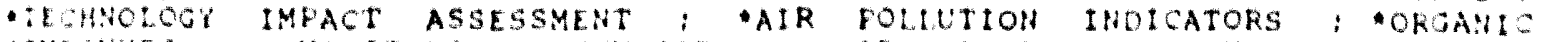
COMFOUNDS; MONITOREHO, ERV-AIR; AIR SAMPLIHC; HAZARDOUS haStE

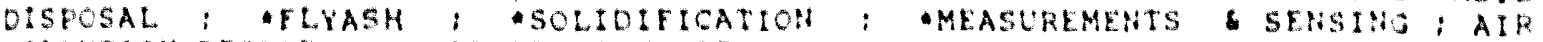
POLLTLON FESEARCH ; HAZARDOU'S VASTES

Reviow Classilleation: ol

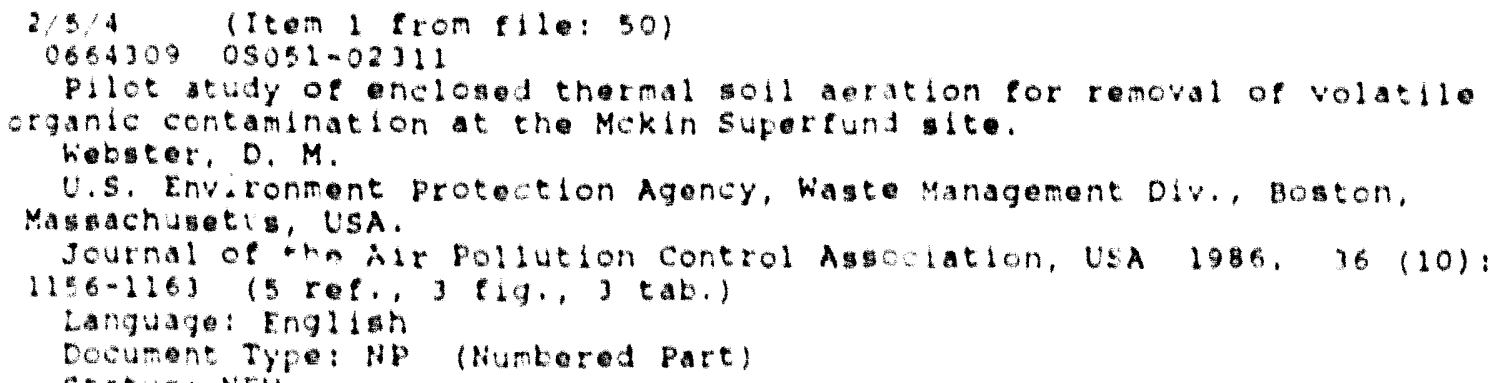


Source: Covt Reports dirouncemerts \& Index (GRAsI), Issue 17, 1589 Jouinal Announcerient: 6911

Toj: The Velsicol chemleal corporation (VCC) is a manufacturing facility located in east-central lllinols, approximately one mile north of the city of Marshall, Clark County, Illinols. A total of 334 acres onsite are leasel for crop farming. VeC was in operation between the mid-1930s and August 1987, and occupled an atea of approximately 420 acres, 172 of which were used for production or disposal practices for fetroleum derivatives including resins, solverts, and pestlcldes, including chlordane nanufacturing. All process wastenater has been deep-nell injected onsite stnce 1965 and the majority of the waste solids and sludges generated at the faclilty were disposed of in Pond 5/6 until 1980 when the firm ceased operations. Accldental and intentional oftsite releases of wastes were noted during the perlod the ponds were in operation. In the 1930s, all conta-inated soll and visually contaminated sediments were consolidated and stabllizec with cement and $f l y$ ash, and covered with a temporary clay cap and vegetston. The primary contaminants of concern affacting the soll, sediments, surtace water and ground water are vocs including benzene and other organics including pals and pesticldes. The selected remedial action tor the sito is lneluded. Final rept.

Deseriftorg/keyords:

Earth llis: Industrial wastos; Site surveys: Hazardous materials; ponds; chemical industry; waste disposal, Water pollution, solid waste disposal, Ground water, Benzene, surtace water, Solls, Aromatic polyeyclio

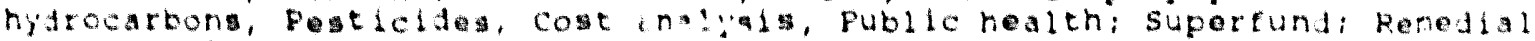
action: Soldd waste mangement; Velsical chemlcal Corporation; Land reciation: Marshall(1linols), Liguld wase disposal, Land disposal, Volat

Order Incormation: UTIS/PBs9-196703, 98p NTIS Prices: PC AOS/RF AOI

$2,6$ (1ten $2 \operatorname{trom} 6110: 156)$

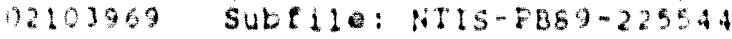

Coneract Nunber: EPA-ROD-R10-85-011

Supertund Record of De:igton (FFA Reglon 10): Commencement Bay iear shore, WA. (first Remodial Act: on), Decorber 1983.

Anon

Environmental protection Ageney, washington, DC. Office of Emergeney and Reredial Response.

E.te日: Covt Reports Amouncenents I Index (GRASI), Issue 22, 1939

Journa! Announcement: 9001

TD1: The Tacona ray Pitg site covers approximately jo acres within the

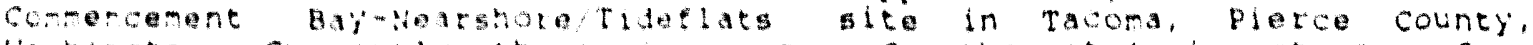
nasmington. C'trentli there is concern for the stces impact on surface

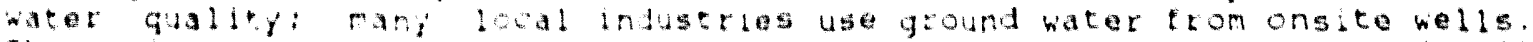
The primary contaminans of consern aftecting surface water and soll inclule: tenzan, Fabs, pcBs, and lead. The selected remedial action for the site includes: exwation of all contaminated solls exceeding li total PAlls and all surtace solls exceedirg a 10 sup -6 lifetime cancer risk level wto stablilation of al! excavated soils in a polymercerent mixture: capeng of tho stablied pattix with asphalt; channeling and fonaging of surse haters: growl water ronitoring; and remowal and treatrent of

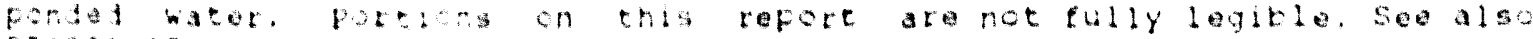
F.3 $3: 41 \%$.

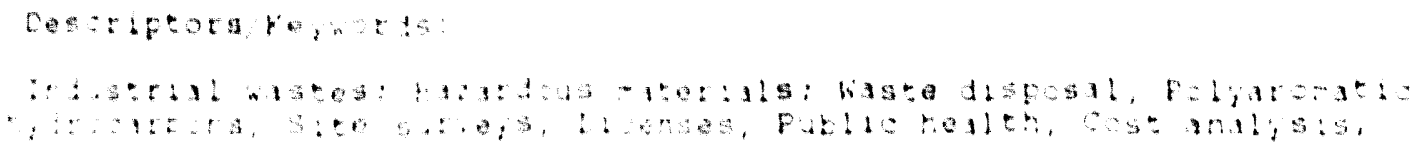


Correncerent Bay, Lead(Metal), hater pollution; Superfund program: Peredia! action: Land reclamation: Solid waste management: Tacoma(washington), Volatile organic compounds

order Intormation: NTIS/PB89-225544, 107p NTIS Prices: PC A06/MF AO1

$2 / 5 / 7$ (Iten 1 from file: 636)

00931328

"Stabilization/solidification of wastes containing volatile organif Compounds in Commercial Cementitlous waste Forms"

Waste Treatment Technology News December 00,1990

ISSN: 0885-003 WORD COUNT: 190

FCBLISHER: Business communications Company, Ine.

(Indexers: Advanced containment)

The report, by R.D. Spence, T.M. Gilliam, I.L. Morgan, and S.G. Osborme (Oak Ridge National Laboratory), and is avallable from :Tris (703-487-4650) as DE90012188/ABS. "Stabilization/solidilication is one of the most widely used techniques for the treatment and ultimate disposal of both radioactive and chemically hazardous wastes but it does not have regulatory approval for treating organics. Application with volatile organic compounds is parcicularly controversial since it was believed that the necessary mechanical mixing and exothermic cementitious reactions would vaporize tre volatile organic compounds. The ofjective of this study was to establish whether stabilization/solidification is a viable alternali"e for a sudge heavily contaninated (about it) with relativily inmoblle metals, but lightly contaminated $(<0.041)$ with volatile ingaile compound that was contaminating the groundwater. The mass balance lilulcated that over 50 of the volatile organic compound was retalned in the laboratory preparation of tr.e cementitious samples cured for 28 days. The performance tests indicated the commercial products could attain leachability indexes from 7 to over 9 for the elght volatile organic compounds studied and distribution coefficients of over 10 could be attalned for all eight and over 100 for some compounds."

COFiRICHT 1920 by Business communications company, Ine.

ENDUSTRY: Environment (EV)

$2 / 5 / 8$ (Item 2 from file: 636)

00969443

Remediation tectinologies touted at llazkat conferenco

SUPEFFUND NOvember 16, 1990 V.4 NO. 24

ISSi: $0872-2985$ WORD COLHT: 637

FLBLISHER: Pasha Publications. Inc.

Success stories ranging from bench-scale tests to full-scale cleanups were offered in a presentation entitled, "Something old, Something New," at tre recent Hazidat hest conference in Long Beach, calif.

In situ volatilization removes solvents lillliam Gallant ot Roy heston sal is company removed atout 3,000 pounds of solvents, cooling oll a:il arosene fron a site in california using in situ volatilization. At the 3.te a 2,000-7allon, concrete-lined tank had leabed halogenated ard at at ic corpounis into a plume extending 95 teet deep.

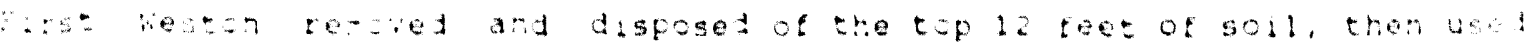

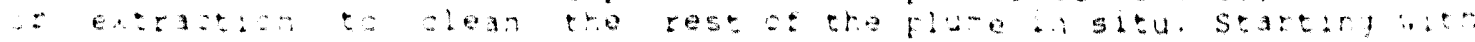


choentrations of $261 \mathrm{mg}$ ig of volatile organic compounda, the syster. cleaned the site to non-detectible anounts.

The in situ system consisted of two vapor extraction wells and seven vacuun monitoring vents. The vapor came out of the wells and through a blower to a heat exchanger before passing through three carbon extraction beds, each with about 500 pounds of carbon.

lieston operated the vapor extraction unit for 21 days to achieve its cleanup goal.

soil washing gets lead out

Robert Evangelista of CH2M Hill described a soil washing bench-scale test for cleaning lead from contamirated soils at battery reclamation sites at Lee Farm in wisconsin and sapp Battery in Florida.

Differert analyses were used for the soils at the two sites because the criteria for measuring cleanup effectiveness differed. At Lee Farm, the goal was less than $5 \mathrm{mg} / 1$ of EP tox lead, while the Florida site's goal has 79 ppm total lead. Ep tox lead at Lee Farm ranged as high as $68.7 \mathrm{mg} / \mathrm{l}$. No EP tox analysis was done on the sapp Battery site.

One of the first things CH2M Hill found it had to do at both sites has to classify the soil according to grain size. Three size categories here used: greater than 0.25 inch, $0.1 \mathrm{~mm}$ to 0.25 inch and less than $0.1 \mathrm{~mm}$.

Aiter separating the soils by size, technologists used ethylenediaminetetraacidic acid (EDTA) in a 20 solution as a chelating agent to extract lead from the soil. The material then passed through an EDTA polish rinse before going through three polish rinses.

The researchers found the EDTA to be an effective extracting agent but the EDTA polish rinse was detrimental to the process. The whole process horked in reducing the Lee Farm E.P Tox iead to less than 5 mg/l, but did not clean the sapp Battery soil to less than 79 ppm.

The researchers also found that incorporating high soil loading with shorter reaction time improves the process elficiency. Evangelista estimated the costs for the system at $\$ 300-\$ 500 / c u b i c$ yard.

John Wesnousky of the California Health Services Dept.'s remedial technology unit reported on a number of case studies of remediation systems in California.

Land farming and stabilization fixes

In two instances of above-ground biological treatment (land farming) systems to clean hydrocarbon compounds such as waste and diesel oils, researchers fourd that while the systers work, adding stirulants to the soll to enhance the process didn't give any better results than the natural oxygention and water added to control piles.

Three California projects looked at silicate/cement stabilization for metal canta-amirated soils. A lab-scale test showed Ensotech's Fater.ted Landtrea: and Enso! products cut concentrations of cadmium, copfer, lead, nickel. zire, silver, rercury, cobalt and chronium as inell as a rixture of copper, lezd and niciel to below the soluble limit threshold concertration (SILC) tar each surstarce as specified in California law.

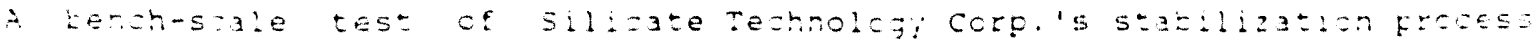


shoied significant reductions in soluble lead concentrations, but a good bit of that may have been the result of chemical reactions that changed the lead to an insoluble solution.

Finally, a pilot-scale demonstration of the Trezek silicate stabilization process reduced leachable metal concentrations of lead, 2 inc and cadmium to telow their soluble threshold limits at the Tamco steel plant in Rancho cucamonga.

COPYRIGHT 1990 BI PASHA PUBLICATIONS INC.

INDUSTRY: EnVironment (EV)

$2 / 5 / 9$ (Item 3 from file: 636)
O0686461
SOlidification releases VOCs
SUPERELND August 28,1989 V. 3 No. 18
ISSN: 0892-2985

PUBLISHER: Pasha Publications, Inc.

Hazardous-waste solidification encourages a massive release of volatile organics into the air, according to research by Acurex corp. and EPA.

Acurex and EPA found that as much as $90 \%$ of the vocs added to test samples volatilized during solidification and as much as $60 \%$ of the remainder volatilized during the following month. Voc emissions during stabilization were significantly higher than from control samples treated the same way except for the addition of solidifying agents.

The researchers created the waste samples by mixing soll, water and latex paint sludge, then doping the mixture with volatile acetone or trichloroethylene, or semi-volatile n-pentanol. Acurex's Leo Weitzman and EPA's Paul de Percin said in a paper they solidified the waste with a $50 / 50$ fly ash/lime kiln dust mix and portland cement.

COPYRIGHT 1989 BY PASHA PUBLICATIONS INC.

INDUSTRY: Environment (EV)

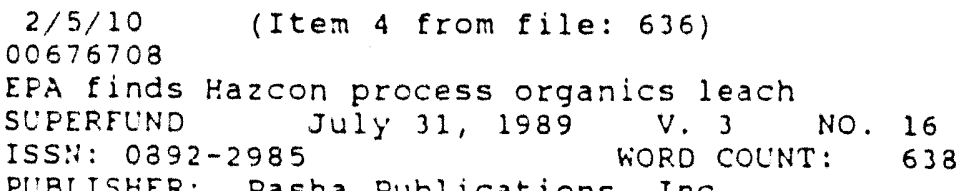

PUBLISHER: Pasha publications, Inc.

Despite earlier findings to the contrary, Hazcon Inc.'s solidification treatment process doesn't immobilize organic contaminants, according to an EPA refort.

Hazcon's process does a great job of solidifying mixtures of soil art concrete in the presence of organics, the report said. Hazcon crercame the froblen of organics' keeping concrete from curing with a chemical additive it calls chloranan. The chemical allowed curing even when organics azcourted for as much as 25 by weight of the soil in a superfuri Innciative Technology Evaluation progeam pilot.

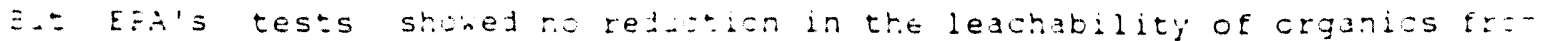


the solidifled mass. A recently completed applications analysis report said these results agree with most other pilot tests of Hazcon's technology. For example, leach tests removed more than 86 of total organic carbon from liquids Hazcon solidified from Rocky Mountain Arsenal's Basin F. But a series of tests the American petroleum Institute sponsored showed the process cut the leachability of volatile organics from refinery wastes by 998.

EPA found the process immobilized heavy metals and produced blocks of concrete that were structuraliy sound. The long-term integrity of the concrete remains unknown.

The agency concluded the best uses for the process are immobilizing heavy retals in soils and sludges full of oll and grease and handiling soll containing lots of immobile organics that needs stabilizing. But if the organics are mobile and toxic, then a treatability test is a must.

Hazcon's SITE pilot at a superfund site in Douglassville, Pa., appeared to have no effect on the leachability or organics. The toxics characteristics leaching procedure removed less than 1 ppm of volatile organics from solls containing as much as $150 \mathrm{ppm}$, with or without treatment. This procedure also leached $3 \mathrm{ppm}$ of phenols from treated and untreated soll. The TCLP nould appear to put solidification at a severe disadvantage, because it involves crushing the solidifled mass, exposing interstitial wastes. But EPA got results in the same order of magnitude with two tests borrowed from the nuclear industry that leave the treated waste intact.

The pilot produced concreted soli with unconfined compressive strengths of 220-2,959 psi - well above the 15-150 psi achleved by competitors and the EPA guideline of 50 psi. Permeability was 10-8 centimeters per second -. an order of magnitude beyond EPA's standard for hazardous waste landeill liners.

But the pilot more than doubled the waste volume.

To get insight into long-term integrity, EPA subjected solidified samples to 12 wet/dry and freeze, thaw cycles, then checked for erosion by measuring weight loss. Results were very low - less than 1t, and a mere 0.3t higher than for control samples.

Microstructural analysis hinted at a long-term prtential for degradation. EPA found the cement matrix to be porous, incompletely hydrated and containing undispersed soil aggregates. This could be a result of insufficient mixing, easily corrected with a more vigorous mixer.

EPA's economic analysis indicated Hazcon's process costs $\$ 97$ to $\$ 205$ per ton. The most important variables are the ratio of chemical and cenent additives to waste and the size of the treatment unit.

cement costs $\$ 50$ per ton and Chloranan costs $\$ 66.67$ per ton. EPA found that cutting back from a ton each to two-thirds of a ton each per ton of waste soil cuts the cost by 23 to to 40 .

Scaling up from a 300 pound-per-minute pilot to a 2,300 pound-per-minute full-scale unit reduces the labor cost per ton fron $\$ 50-\$ 65$ to $\$ 6.50-\$ 3.50$, reducing total cost by 278 to $40 \%$.

:iext in importance is the on-strean time: Hazcen hopes for 90 , the covglassille pilot was up 708 of the time. The difference changes tro :s: $3: b_{y} 2 \xi$ to $12 \%$. Analitical costs, equiprent rentals and consurables ilso affert the botton lire. 
Fo: a copy of the Hazcon pilot's applications analysis report, wite EFA's Center for Environmental Research Information at 26 kest Martin Luther king Drive, Cincinnati, onio 45268, or call the SITE hot 1 ine at $800-424-9346$ (382-3000 in hashington).

COPYRIGHT 1939 BY PASHA PUBLICATIONS INC.

INDUSTRY: Environment (EV)

$2 / 5 / 11$ (Item 5 from flle: 636)

00633038

DOE FIVE-YEAR CLEANUP PLAN TO FOCUS ON NEW TECHNOLOGIES

HAZARDOUS WASTE NEWS APEII $10,198 \mathrm{~S}$ V. 11 NO. 15

ISSN: $0275-374 X$ WORD COUi:-: 759

FUBLISHER: BUsiness Publishers, Inc.

Deflecting earlier criticlsm that the Department of Energy is 111 -equipped to head the cleanup of contaminated defense plants, Energy secretary James fiatins told Congress that DOE's flve-year waste management and cleanup plan will include a major efort in researching and developing new cleanup technologles. The plan is due in August.

Watkins, before a House Armed Services panel April 3, outlined the plan which he sald will "help re-establish DOE's credibility with the public and with the states" on defense plant waste management.

Removal of DOE's Cleanup Role suggested

fatkins' defense of DOE's cleanup of defense plants followed a March 15 rearing by the senate Budget Committee, when Chalrman James sasser (D-Tenn.) warned that "If DOE cannot make a clear and convincing case that it has the expertise to handle this program and does not develop a credible environmental plan within the year, I believe that serious consideration should be given to removing the cleanup responsibilities from the Department of Energy and placing them in a separate entity."

Watkins said DOE will work with the National Academy of Sciences and state and federal requlatory bodies to: assess the extent of environmental degradation and impairment; establish priorit.es to immediately address potential health effects and to prevent furtrur spread of contamination; and establish a research program to fund development of the best and most critically needed technology.

The department also will develop a remedial action plan for each site: work: with congress and state regulatory agencies to meet cleanup requirements: and recommend sources of funding and methods of oversight to ensure that resources are effectively used and that program goals are achieved.

Part of Watkins' environmental plan calls for new emphasis on technology develcprents to keep pace with environmental cleanup requirements. The department will seek to mininize waste currently produced, and develop technologies in cherical extraction and bioremediation, watkins told tre Arred services' DoE Nuclear Facilities subcomittee.

to conduct cleanups, robotic-applied technologles are envisioned to reduce hazards to horiezs engaged in decontanination and decomissioning hork.

Las: weeb, re sa! s several new techrologies are being pursued at doE sites tased cn eftectiveresa, afplicatility to current envircnoental problems ard

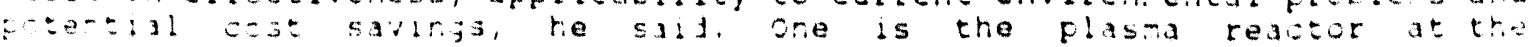


Yagnetchydrodynamic Facility in Butte, Mont. The reactor will treat hazarjous waste at temperatures in excess of 17,000 degrees rahrenhelt to treak doin the hazardous naterials into carbon, hydrogen and oxygen. This is an advanced technology that may apply to future cleanup activities, iatilins added,

:acuun extraction of trichloroethylene (TCE) at Lawrence Livermore liatlonal Laboratory (LLNL) site 300 is showing effective cleanup of ground fiater contaminated with solvents. TCE In pumped ground water is being destroyed $k y$ an ultravlolet treatment system at the kansas city plant. A pllot vapor vacuun extraction system at the main LLNL slte has demonstrated removal and destruction of over $3,000 \mathrm{lb}$. of spllled gasoline hydrocarbon contaminants in the first 200 hours of operation. DoE is also testing in-situ vitrification, detoxification of haste acids and supercritical water oxidation of hazardous organle solvents.

litkins also outlined work alreaty completed or planned at a number of sites:

Savannati Rlver Plant, Aiken, S.C. The closure plan for seepage basins F and $H$ is beling reviewed by the state and the Environmental Protection Agency. Etforts will begin next year to backelli and install a clay cap in accordance with RCRA requirements. The effluent treatment system began oferations in November to liminate the discharge of separations process waste waters to seepage basins. Ihls facility represents state-ot-the-art technology in filtration, ion exchange, reverse osmosis and evaporation. The M-Area settling basin closure is in progress and will be completed in 1990. This will eliminate the direct discharge of untreated liquid wastes to the environment. Construction will begin in elscal 1990 on faclilties for the solidification and permanent disposal of waste salt solutions from the $300-y$ area tuel fabrication tacility.

Rocky Flats Plant, Denver, colo. Sludge is belng removed from the solar Fonds, with final closure scheduled for 1996 . Ground water contaminated with volatile organics from the 881 Hiliside area is scheduled tor tratment and reinjection starting this year. All deadlines have been met so far in the compliance agreement with the state and EPA. Shipments of transuranic waste to Idaho have been resimed.

Hantord Reservation, Richland, Wash. Ef forts are underway to meet tri-party RCRA compliance agreement requirements. For example, last August, tre grout treatrent facility began solidification of liquids stored in double-shell tanks. Some 35 ground-water monttoring wells in 1989 and 45 additional wolls in 1990 will be installet in the single-shell tank farm. The prefaration of 58 RCRA Part 8 operating perits is underway to reet the 1990 RCPA deadiline.

COPIRIGHT BUSIHESS FUBLISHERS, IHC. 1939

E:TOSTRI: Environment (EV)

$2 / 5: 12$ (Item 6 from f:le: 636)

0054538

Eph ants to solidify saco hastes

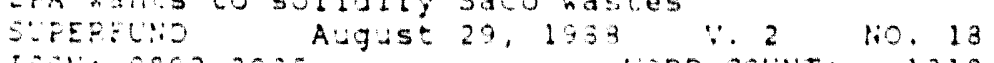

Iss:: 0852-2935 hORO Co6its: 1218

Fisure: Pasha futlicatiors, Ire.

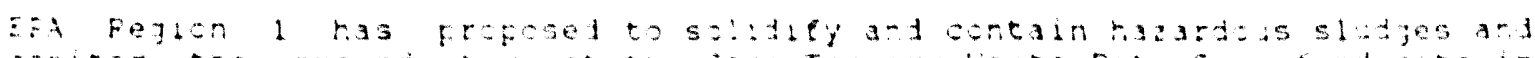

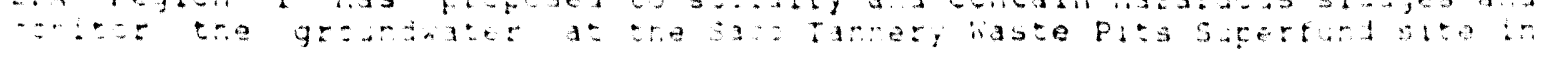


Saco Maine, at a projected cost \$33.5 nllilon.

A leather tannery had dumped process wastes into two unlined lagoons and 53 pits at the site from 1959 to the erly $1980 \mathrm{~s}$. The wastes.- chromium sudges, solvents, acids, caustics, leather shavings and tides -- pose a threat of soil, surface water and groundiater contamination.

After putting the ste on the superfund 1ist, EPA in 1983 sent in removal contractors who removed 6,600 gallons of acld waste, neutrallzed remaining sludge with 1 ime, capped it and erected a fence. A subsequent $r i s k$. assessment concluded no one should develop the site residentlally without a cleanup, malniy because of risks from direct contact and drinking greundirater.

EFA isolated two cleanup goals: to reduce concentrations of 11 rey centaminants to acceptable levels and to immobllize chromfum oludges that present a groundiater threat.

The ageney wants to spend $\$ 33.2 \mathrm{~m} 111$ ion on the source control remedy. EpA nould truck away standing water for off-glte treatment, excavate the sludge for on-site sclidification and bulld a RCRA landfill to hold the solidifled s! udge.

As for the other source remedies mulled:

- a $\$ 5.9$ mililon soll cover would reduce the direct contact threat, but wouldn't halt leaching or involve treatment;

- Eleld tests gave EFA "serlous reservations" about the offectiveness of a $\$ 14.8 \mathrm{mlllion}$ in-sltu solidiflcation remedy:

- solidification alone (\$27.2 million) would be too risky, sinco orosion could crunble the soliditied mass;

- on-site landelliling alone ( $\$ 28.5 \mathrm{million})$ would te tough because the sludge is so sott:

- or-slte soil washing, the most expensive option considered $1 \$ 105.6$ M:110n), would simply concentrate the contaninants and hasn't been de-orstrated for sludge treatment; and

- on-site incineration (\$91.3 million) would te fine, except it could cxidie the chromium, making it more toxic. EpA contractors developed a fest-inclneration chromium recovery process, but it needs more work.

EFA offeret an interesting resson not to treat groundiater: since contarinat levels are fairly near the cleanup targets, EPA could reach the tagets without treatment simply by pumping. Clean and dirty water would enter the extraction wolls and $m i x$, producing acceptably clean water.

The EFA projest manager is Marina Mejer at 617-573-9638.

- July proposes of -site disposal remedy

:3!ir corp bas proposed an off-site disposal reredi for the rost o-a-inated sil at a sufertund site in Mimnesota.

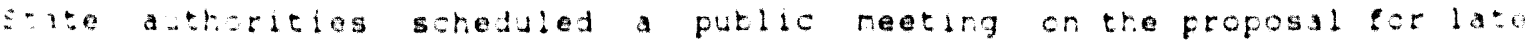
$3.5:$

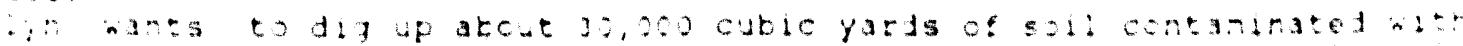

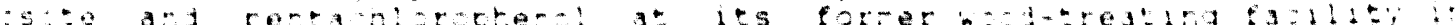

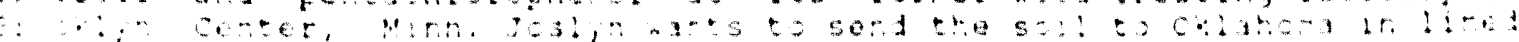


ant covered rail cars. The comany expects to send so rail car loads.

sosijn wlll leave less-contaminated soll alone unt 11 the company completes a resedial investigation and feasiblitity sudy of the site.

The Minnesota Pollution Control Agency approved a groundiater pump-and-

treat renedy earlier this year for the site. A contractor is bullding the $f a=i 1 i t y$.

- Government breaks off SRSNE talks

EPA and connectlcut authoritles have given up on cleanup negotlations with the owners of a superfund ite in southington, conn.

EPA has started a remedial investigation and foasiblilty study with federal superfund money. EPA and Connectlcut Dept. of Environmental Protecticn laitiers plan to pursue legal remedies under superfund and RCRA.

The government broke of negotiations after declding solvents Recover; Service of Nen England (SRSNE) had inadequately rosponded to a request tor short-term improvements at the hazardous waste facility. EPA and the state had tried to work with the company to get it to improve operations, remedy the site and comply with regulations.

The company has distliled and recovared solvent at the ste ince 1935. The elty of southington lnstalled two drinking water hells within 2,00 seet of the site, one in 1965 and the other in i976. The state determired in 1976 that both tapped water contaminated with volat lle organic compounds (VOCs). EPA later conelrmed the vocs came from the solvent recovery operation.

Key contacts are Ed parker at the DEP and Maggle Leshen with EPA Reglon 1 in Boston.

- EPA wants to blo-treat New Mexico site

EPA has proposed bioremediation for a superfund ste in Clovis, N.M.

The operators of a sitchyard in Clovis along the Atchison, Topeka a:l santa Fe (ATSSE) rallroad have dumped wastewater linto the santa ro labe since the early 19003 . They washed rallway hopper cars at the switchyart from 1962 to 1982, discharging water bearing residues from potash, cenent. tertilizer, grain and coke into the playa lake.

EPA added the lake to the supereund National priorlties list after cencer: suraced in clovis that the lake's dirty waters night harm underlybl g:oundiater -. the town's sole source of drinking water.

The agency has sirce decided the groundwater is clean. But to matie sure it s: iys that wai, EPA will remedy the surface contamination. EPA cound hith ¿e as of arsanle, boron, chloride, fluoride, phenolics, sulfato, disselvet s. is and organic compounds in the labe's waters. Epd also cound tha. t:an, barium, lead, chromium, hydrocarbons, phenolics and organics tat a ancra:olir the late sediments.

E. proposed to trunster contanination tron the labe inters to the t: i ar of sedizents at a cost of $\$ 400,000$ by spraing the water ontodr. : : s of the strirkirg labe's bed for evacoration.

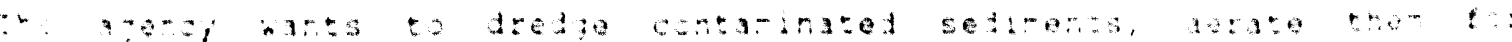


wodegradation of sulates and fetrolein frotucts and cap then. Eid p. apital cost at $\$ 8: 2,000$ and operating costs at $\$ 270,000$ for the titse three jears and $\$ 54.000$ lor the lollowing 27 years. EPA wats to biorerediate solls in place by aerating then and adding nutriants at cost of $\$ 42,000$ for the first year and $\$ 116,000$ over the next 29 years.

EPA also consitered fixation remedies. Although fixation would do setter $j o b$ on inorganics, the process often doesn't fix organtes and roslon could eventually rea all the contaminants, the agency sald.

Tim Underwood Is the EPA Region 6 project manager for the ATs5 ate $(214-655-6735)$.

- EPA proposes Unc groundwater ramedy

EPA Region 6 has proposel an $\$ 8$ militon to $\$ 9 m 111$ ion purp-and-treat reaty for the inited Nuelear corp. Superfund ite a mile south of the liavajo indian Reservation in liew Mexico.

United liuclear corp. pumped 3.5 million tons of wet, acldic uranlum mill talling into ponds at the ite from 1977 to 1982 . The liquids have ince seefed from the unlined ponds into thre underlying aquilers. A dam of one of the ponds burst in 1979, sending 90 militon gallons of tailings and water into a stram. Two jear later the ite hent onto the National Priorlties Liat.

EPA plcked the simplest and least expensive of three options for groundwater extraction well conflguration. The other two optlons wolld have pumped more water from more aquifers. Also, Epa chose a mistor/pond evaporation treatment alternative over a column evaporation alternativa because it is cheaper.

overlappling furlsdictions have made the cleanup mora adninlstrativeli complex than rost. Besides beling a superfund stev, the faclilty comes under the Nuclas Regulatory commision's mill licensing authority. The company has proposed a roulation plant to NRC. EPA hopes to integrata that plan and ary work: dono under EPA's aegis.

EPA took samples last year that demonstrated groundwater contaninatjon hasn't exceades cleanup standarda.

COPIRIOHT 1983 BX PASHA PLBLICATIOHS INC.

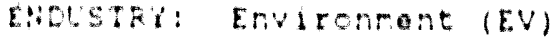

$2 / 3 / 13 \quad(1 \tan 7$ from t110: 636)

$00: 29055$

- Hazon SITE tast stows good rasults

SUPEFl:O0 Juna 20,1930 V. 2 Ho. 13

ISS: $0892-2335$ WORD COUHT: A48

PLEL:SHEP: Fasha Publications, Inc.

Prelininary rosules aro in from a successtul supartund innovatio Tortrology Evaluston (SITE) progzan test of llazon Ine.'s soliditication tectnologi at the Douglassvilie superfund site in Douglassyllia, Pa.

the technology ras sicceeded in encapsulating the sito's rostlyorganto

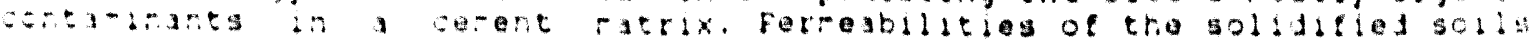


rate from 10(-3) to $10(-9)$ centireters per sewond, well in:o tre "irfetreable" range.

the materlal demonstrated unconeined compresive strengths of 200 to 1,500 p. - with the most comprosive material contalning the least organlus. Hacon attributes the high compressive trength to it chloranan adiltive, - lowo which some of the samples would have has no compressive atrength.

EPA's toxiclty characteristics leaching procadure winnowed a leachate cotaining a mere 1.5 ppm or less of ach metal, and volatile and semplatile organle compound. Original concentrations were in the 100 ppo range.

EPA' laboratory has o tar ten unable to quantify the polichlorinated biphenjl (PCB) content of the leachate. The lte generally contains co ppa of PCBs. EPA had injected the test ollswith 125 ppr of toluene and roults how the leachate contalna 1.J to 2 a per of toluene. Oll and qrease cchtent of the leschate is only $0.2 \mathrm{ppm}$, even though oll and grease acount to: 251 by welght of the contaminated soll.

No metal concentrations were detoctable in the leachate, excopt lor los and inc. load content dropped tron a high as 24.000 ppm in the voli to 10-50 ppm in the leachate. The leachate contalned about the waro amount of and.

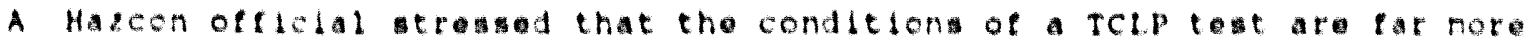
strimgont than would likely be encounterod by a large block of solidifled oll burled in tho ground.

Attor ix month of burlal, tho 10-cublemeter conctete block will be weovered and coted agaln. EPA' stre contractor, Enviroponse, will look to: lins of degtadation of tha blocke.

The treatment yrocen was testod for four day In october 19al, fust weabs atter an artlele in superfund tocused on majo delay cauned by the lack of rejulaton allowin Hazeg to tak amples to lt llouston latoratoty tor

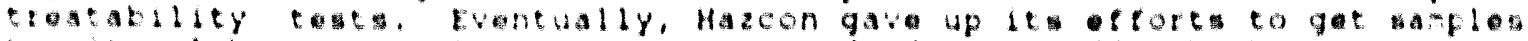

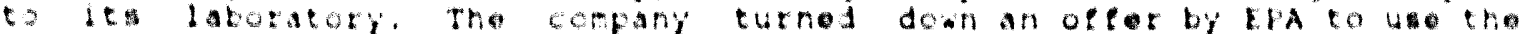

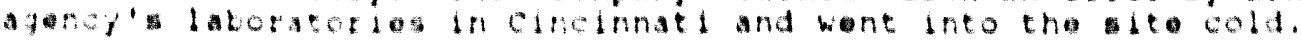

To acesunt for unoxpeted varlations in waso concentration, llazcon vet coservalve ratios in its cementoll mixtures. hille thl bolstered the

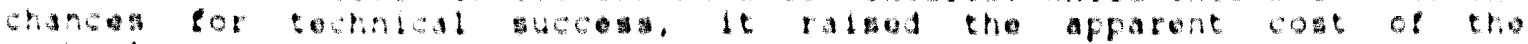
tonotomi.

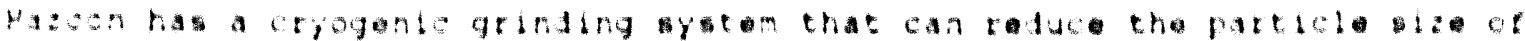

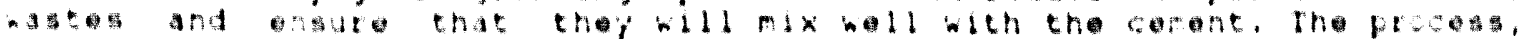

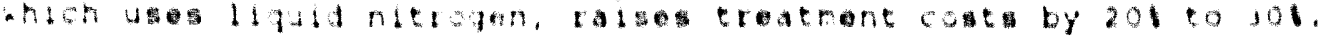

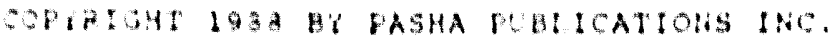

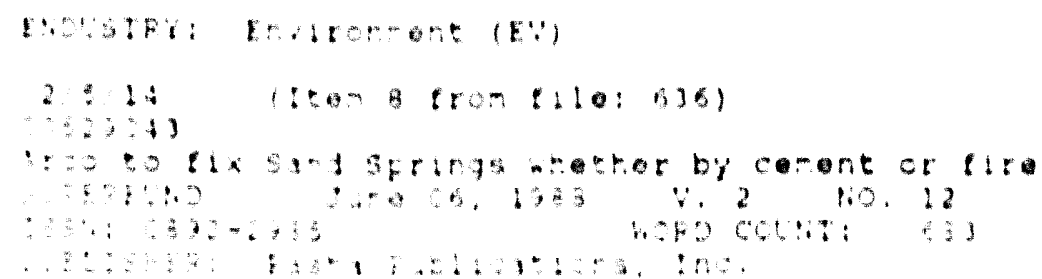


Allatic Richtield co. has consented with EPA Reglon 6 to tecely an oblation lte by incineration or stablileation - whichever Ef prefers after seaing the reults of a stablization demonstration project.

Atco, one of 300 potentially tesponsible parties identified by tha, has areed to perforn the remedy at its ow expense and repar fPA tot ane 1.7 nillion in past costs.

the consent dectee, which tra hodquaters and the Justlce vept, have jet to review, sets a path tor tesolving a lundamental dispute over the remely cot the sand springs petrotiemical complex in sand springs, okla.

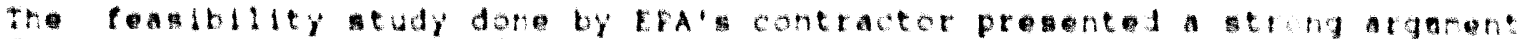

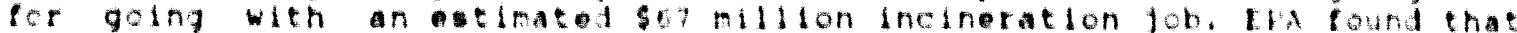
inclnetation meots the mos cleanup criterla. But Arco proposol to renedi the lte by sollditying the hazatdous wastes with coment, which lpa profocted would cost $\$ j$ million. The atate and local cltizens suppot Atco' proposal. Arco has backet its proposal with an unlinlted waranty It the remedy over lalls, the company will return and do "whatever lo aftroprate" to remedy the bite.

The agency dinlike the solldibation alternative becauso it lias not bees

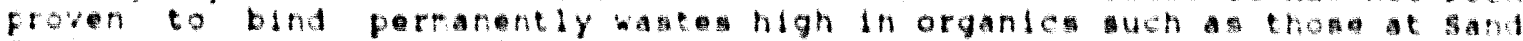
sptinge. Plus, an Arco pllot tos showed the tabllized wates hould libely

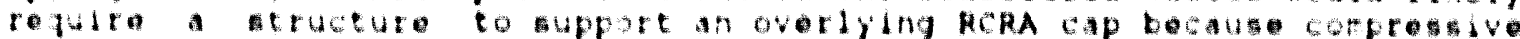

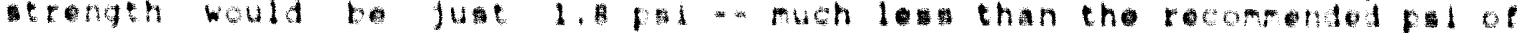

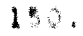

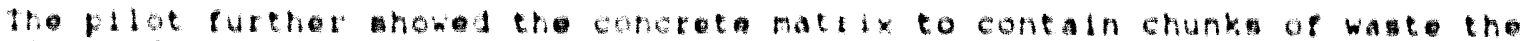

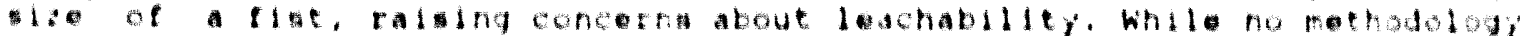

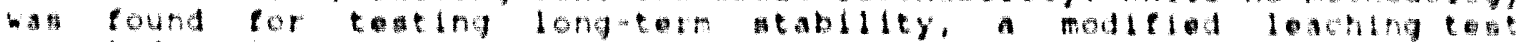
rovales obvious degradition to the coment matrix.

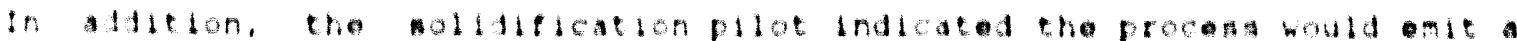

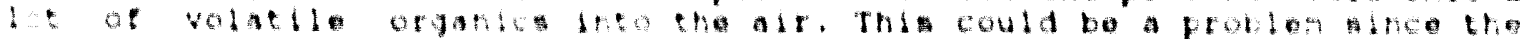

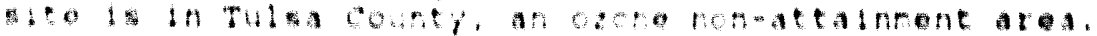

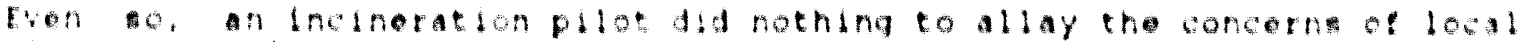

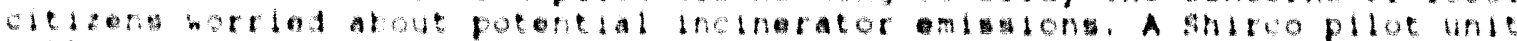

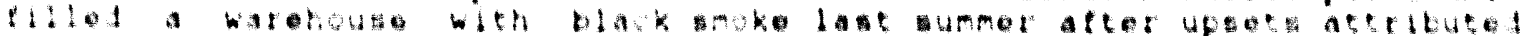

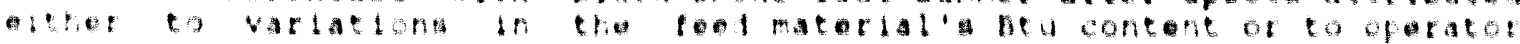
ertat.

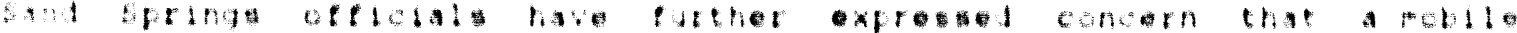

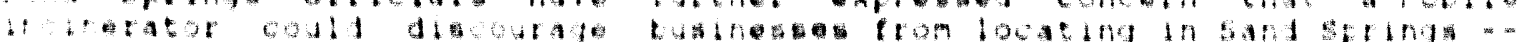

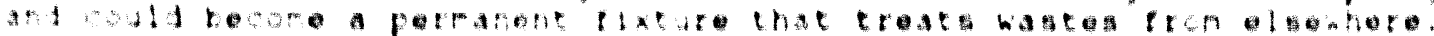

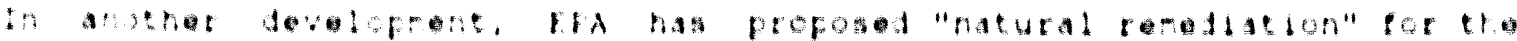

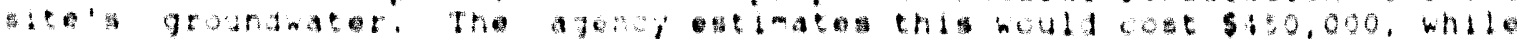

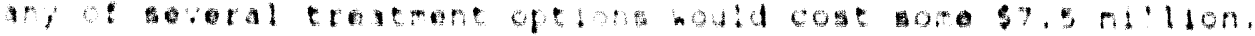

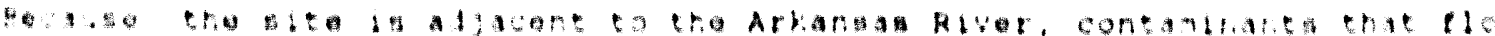

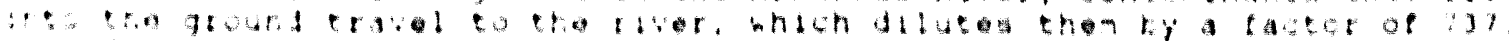

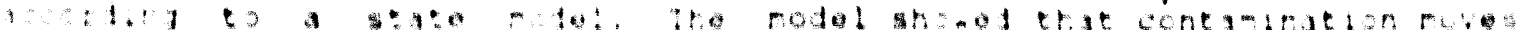

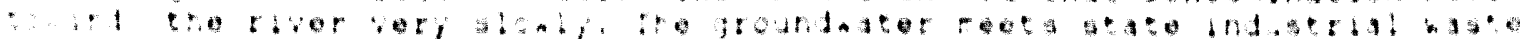

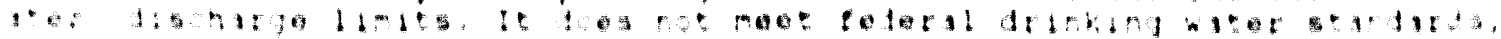

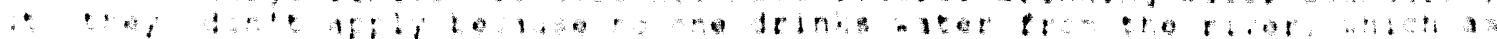

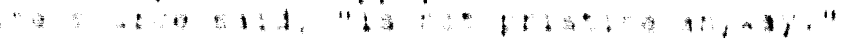




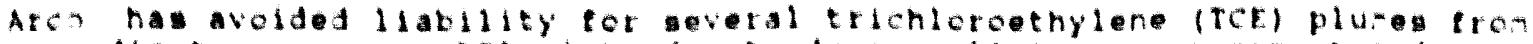
upqradient outces. TPA intend to do a preliminary assosment and lite inspection (PASI) focusing on the plumes, which could emanate from any of i2 upqradient Induseries.

The lte is on some 25 to 50 leet of alluvium along the Arkansas River. Beneath the and is the coterville cotmation, a thick shale with thin tongue of andatore.

A. oll refinery wa operated on the 235 acre alte through the 1940 by sinclair. Which later merged into Arco. A obvent recyclet operated in tre late 1960 and early 1970 at the clen wyn oubalte. The light liquld organie at cien hynn will be inclnerated of elte if the bulk of the ste' 130,000 cuble yards of wates ate ctabilized. The Hite has several crousand cuble yards of mulfurle acld ludge in unlined plts. The pH is 2.1. Also, lagoons, plto and pray pond contain heavy retals and organies.

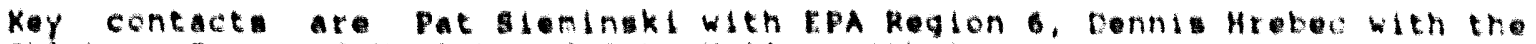
oklahoma Dept. of Healeh and John Miller with Arco.

COPYRtCHT 198 BY PASHA PUALICATIONS INC.

lNotstRY: Envitonment (IV)

$2 / 515$ (1tem from tile: 63)

0050207

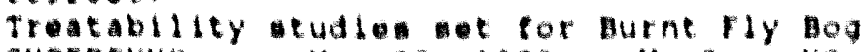

SLPERTUNO MaY o9, $190 \mathrm{~V}$ V. 2 No. 10

ISEN: OBg2-2935 WOAO cotNT: 53

putishtri Pasha Publicatione, Ine.

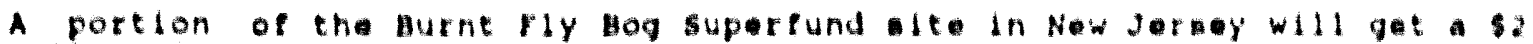
milion interim contalnent remedy and treatablity tonts of rour treathent tochnoligles, It the etate has lto bay.

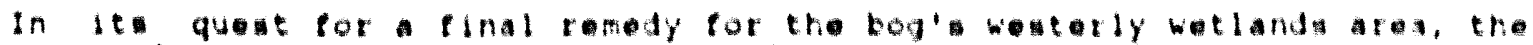

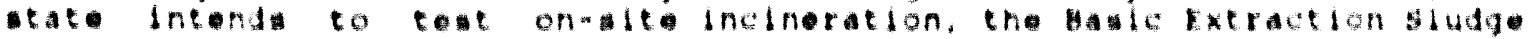

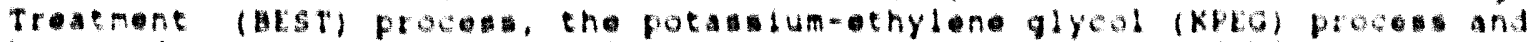

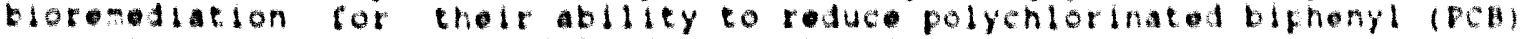
corcontrationa to $5 p$ and loas concentration to 250 pp.

Tho liow Jerey bopt. of Enviromental totecton has proposod to surrounl the hesterly wetlands ates of the 1,700-acte boj with a tance abd ptovlde a gitel abess road. At the downgradient end of the aroa would go a wadiment

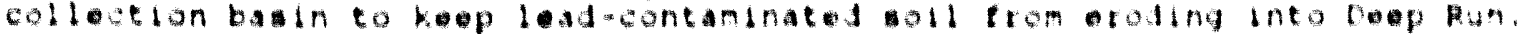

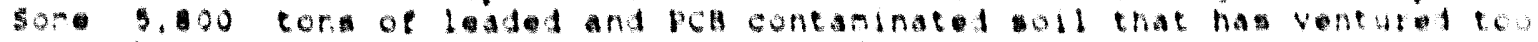
near the trean hould have to te oxeavated.

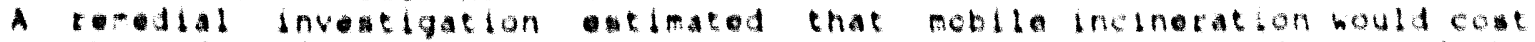

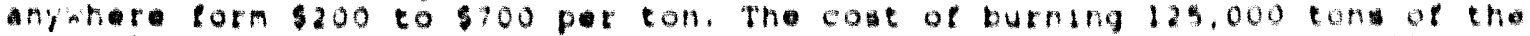

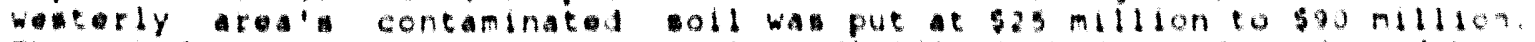

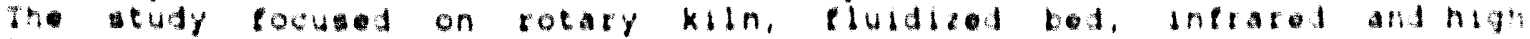
toretature pyrolyin tohnologles.

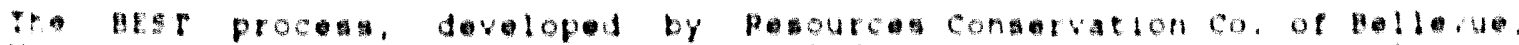

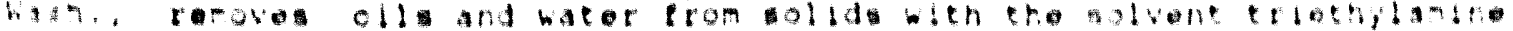

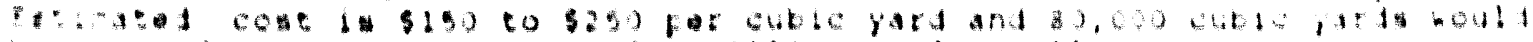

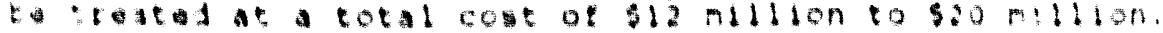

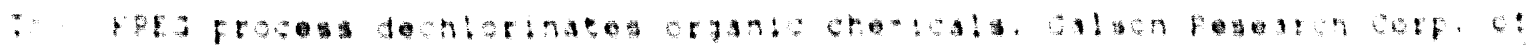

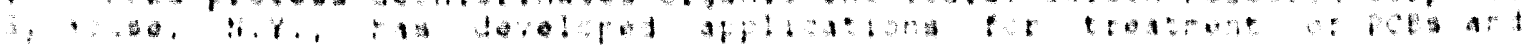


thalns. The process would have no eftect on load.

cost is put at $\$ 100$ to $\$ 200$ per ton of contaninated soll. 16100,000 ton - tre treted, total cost would bo $\$ 10 \mathrm{mill}$ ion to $\$ 20 \mathrm{mill} 10 \mathrm{n}$.

The tate intende to try blotemediation proceas developed by blo-

clean Inc. of Webster, Minn, Dlo-clean destroy pcas and other otganic tu* not lead - - by mixing the contaminated oll with alr and naturally af a microbes in bacterial digenter.

A. a cost of $\$ 250$ per cuble yard for 6.000 cublc yarda, the estirated cionup cost lo $\$ 16$ milion. But that does not count material handing. lo tixation and water tratnent.

These four technologles are among it linalists of 50 orlglnal contestants. ir itate refected inmltu vitrilleation and fixation/solldilication because they would destroy wetland and unpredletably affect the local nydrogeology. The tate turned down ultrasonic/utraviolet treatment becau of It especially early stage of development.

Meanwhlle chemical Waste Managertent inc. Is set to begin a $\$ 3.2$ milldon

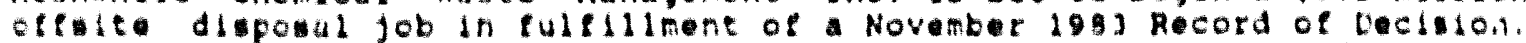
cherinate will remedy the bog' upland area, where several hazardoci hasto ageris toltow "ubtio ridge."

chorwate will remove 10,000 ton of ludge and chenlcal wastes, 40,850 ton of contaminated gll and debris and 500,000 gallon of llquid wate contalning PeBs, lead and volatile and onl-volatlle organles. The comaly wil mix the ludas with soll and kiln duet in coment mixers por atablization prior to of elte dispeas.

cteos International of Buttalo, N.Y., will take tha wates to din iacliley

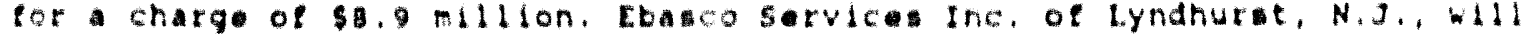
overs the job.

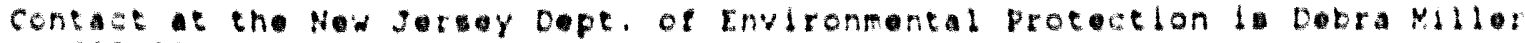
at. $601-91+-3081$.

COFIRIGHT 193 a B PASHA PLBLICATIONS INC.

EDSETR: Envtronment (EV)

$2 / 15$ (ttem $10 \operatorname{trcm}(110: 6) 6)$

$005+133$

Elspet sver remody brings Mich. talks to halt

SPEPENO reteruary $00,1938 \mathrm{~V}, 2$ No, J

ISS: $0892-2903$ WOPD COLit: 634

PLL:SHER: Pasha Putibetoris, Ine.

A disfue over the randy kept negotiator trom reaching a set ch the

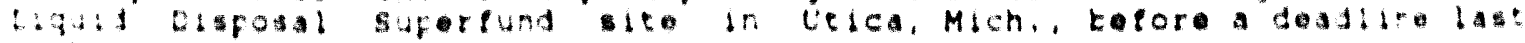
*a)

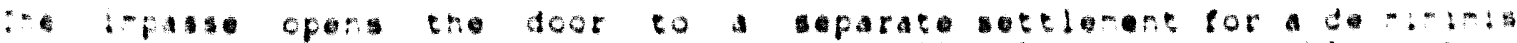

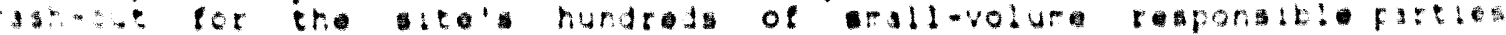

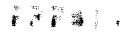

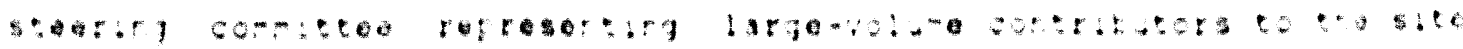


favors coll flushing over the $\$ 22$ million golldiflcation, contalnent and groundwater treatment remedy EPA chose on sept. 30. The PRFs say their resedy would be more appropriate and would cost only ha as much.

In settlement talk EFA has offered to allow the steerliy committee to fund reredial design cor both the remedy it likes and the sne $x$ pa chose, then let EPA declde which to act upon. The comitter declir d, countering with an $\$ 19.5$ million cashout proposal that EPA tound unaccer $=$ able.

EPA's chosen remedy I to solldity contaminated soll and waste materlals with $l y$ ash and portland cement to "greatly reduce or elininate" their mobility. and to furthe protect agalnst mobility by surrounding the sollditled materialuwith a lurry wall and coverli the pllowith an Impermeable cap. Thewall and cap also wlll protect the file from eresion by lightly contaminated waters flowing into the sle. Ir, remedy also calls tor groundwater pumplng and teatment with activated car on.

In EPA's VIew, solidifleation works well on heavy motals and might work tor the low concentration (les than 11 or $10,000 \mathrm{ppm}$ ) vocs in the soll given the use of certain propriatary additives. If not vacuum extraction orsome other process may be nocessary to supplemen: solidiflcation by removing volatile organica.

EPA reognlzed, however, concerns expressed by Mich jan ofelelals that vacuum extraction would not work well atthe ite becasse the boll is not unitormly permable.

EpA did not consider soll tlushing in the thal remedj solocton procass becuse it would involve circulating a large volume of jroundwater. sinee the upgradient groundwater is slghtly contaminated, tis "would have an unknown effect on the local groundwater nystem," EPA sale in the ROD. PJus, - ll lushing would be Impeded during Mlchlgan's long, ec:d winter.

The responsible partlos also contend there is no noed so ramedy ashallow donngradient aqulfer because the aqulter ds so salire that ltshould be clasitied a an unuable class III aquifer. EPA bellevas the aquifer can bo -and in lact inused for drinking water.

Regotlations have atretched without result over a 60 -iay perlod, plus a 10-day oxtengion, during which EFA was not allowed to boiln ramedial work. t.. Woncy is tro now to begin the ostmated two-

year. \$500,000 reodial design process.

De minimis cashout hopes revive while the Pko steering conmittee and Eph trid to iron out thair ditcances on remedy, they defcred tho volatile patter ot a de minlmis eashout settlerent. Shortly atter Eid lssued lts ROD, tha teering combltee hal proposedto the ste's20 PRPs settlement with - de mininis cashout offer. Tha de minimis parties rotidly rejected the otsor.

the allinolume parties organizod aroup, small compantas organized to liogetate an Envitonzental settloment (scoiss), ind proposed a coumer-offer.

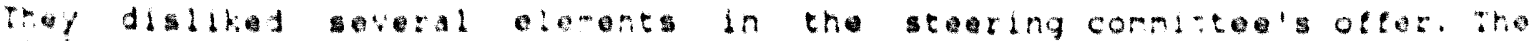
1. 1to 1901 prem bus too high. They prefarred de:ining do -ini-is

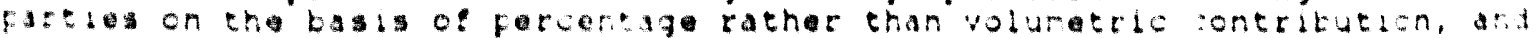

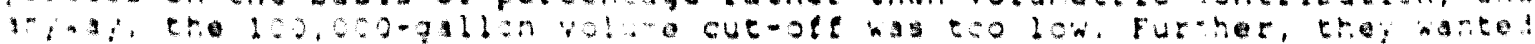

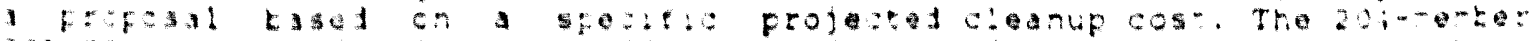

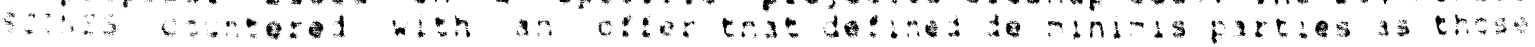




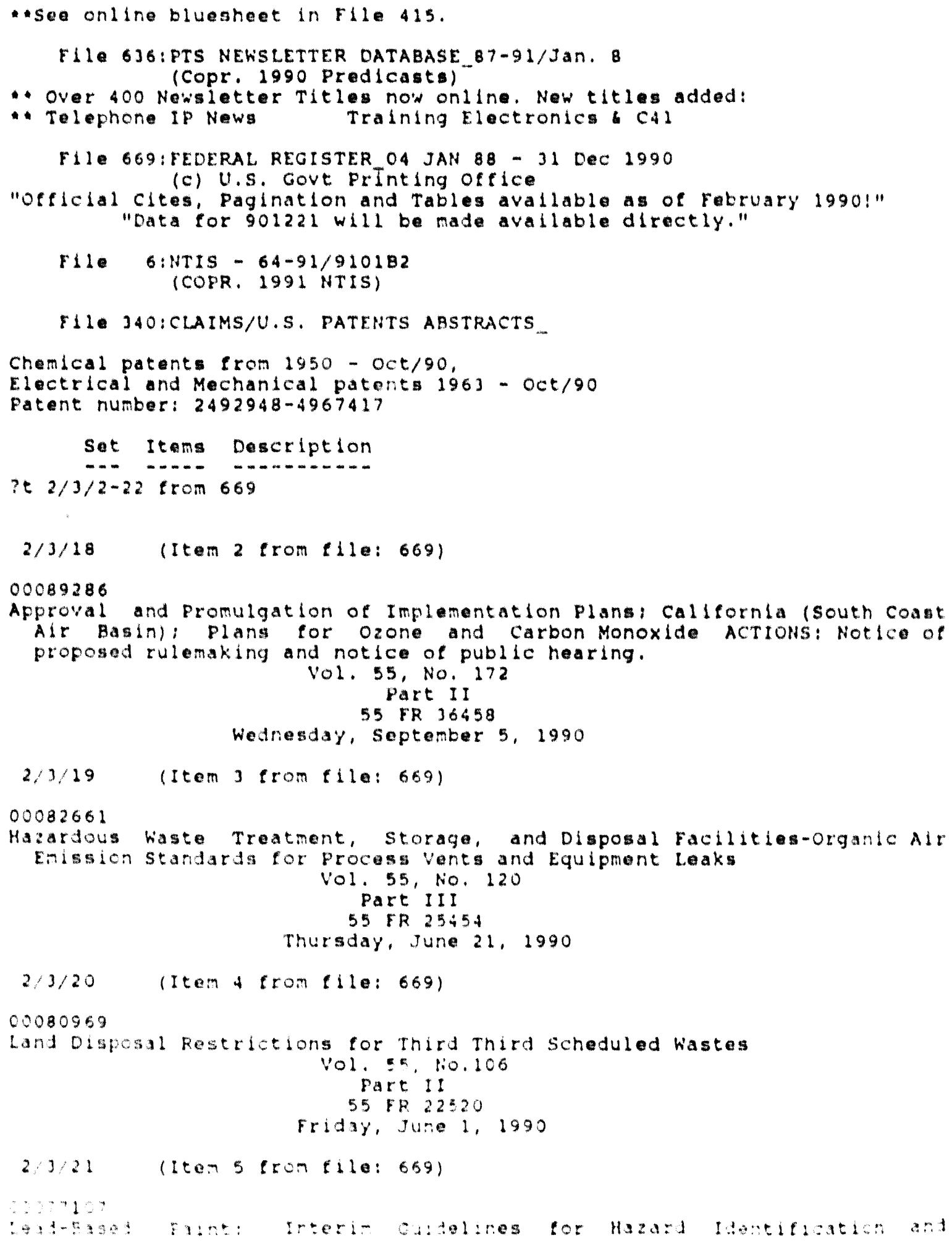




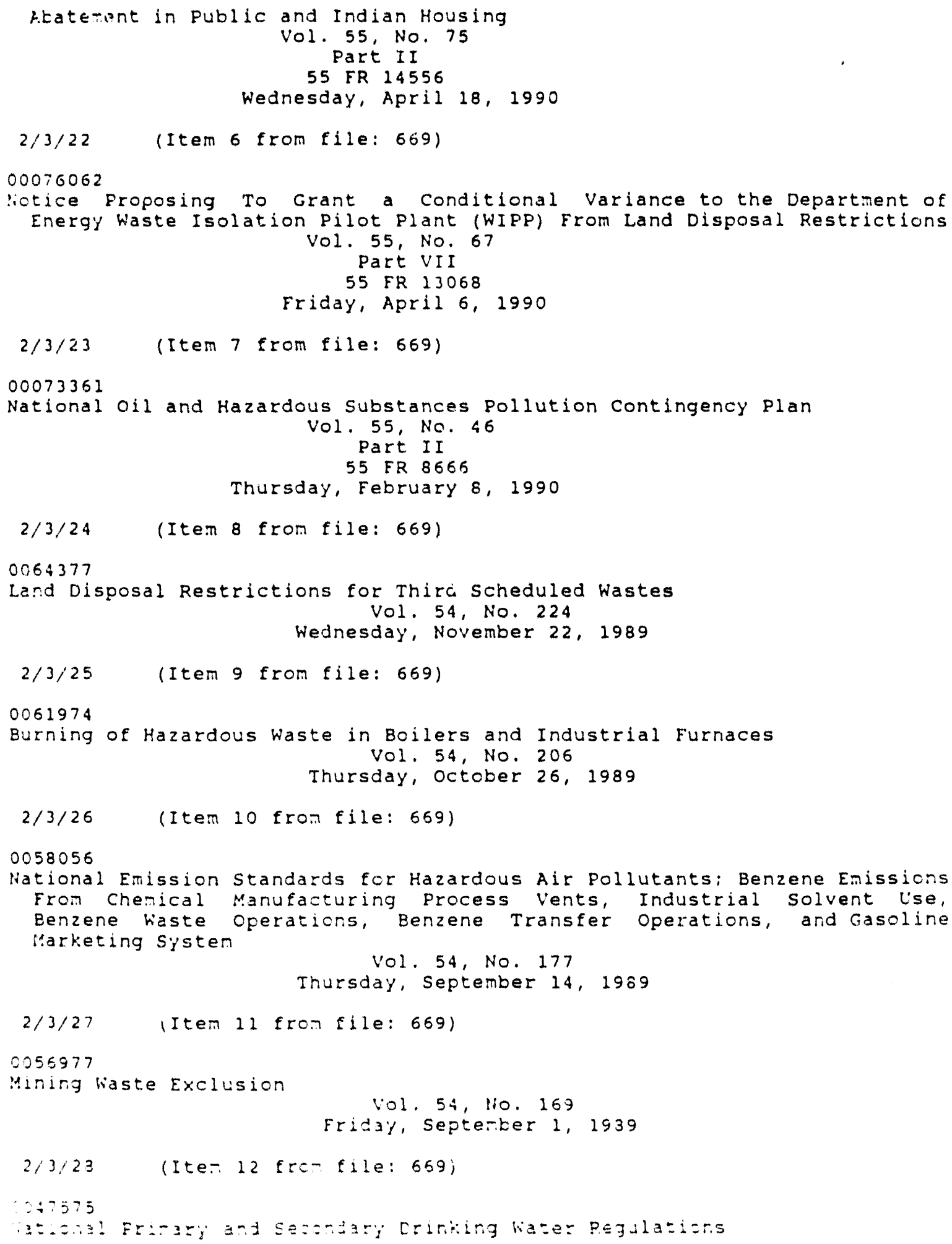




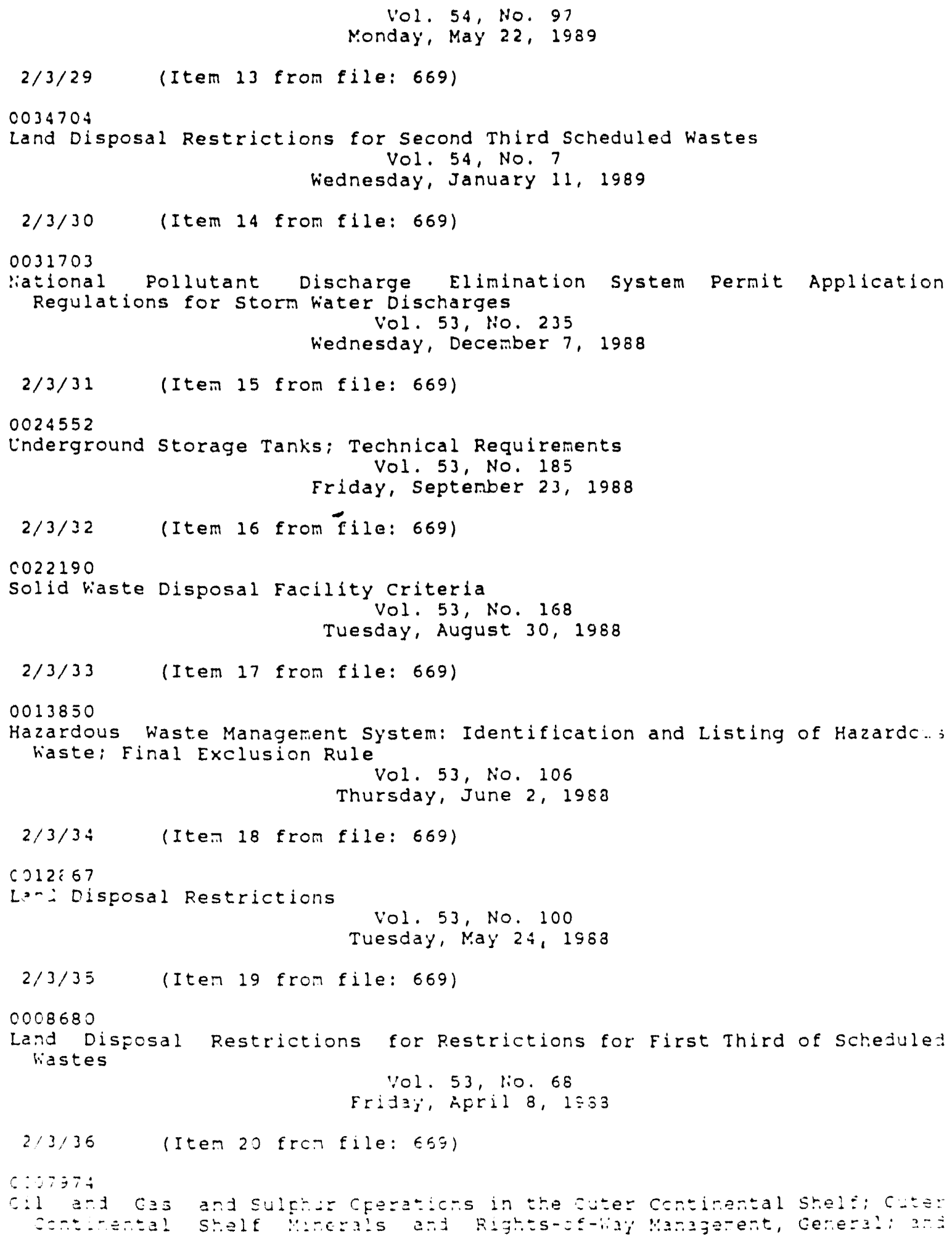




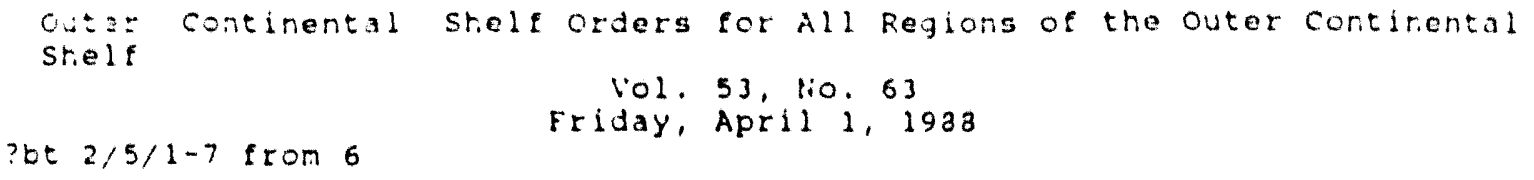


$2 \rightarrow$ Aft $88 \quad 58 \mathrm{p}$

Languages: English

Journal Announcenent: GRAI9007; NSA1300

Portions of this document are 11 legible in microflche products.

NiTIS Prices: PC AOA/MF AOI

Country of Publication: United states

Contract No.: ACO4-760P00053

This report evaluates the use of a joule-heated glass furnace to treat

four Rocky flats plant waste streans. These streams are extremely large, are primarily water soluble inoranic salts, and can be contaninated with hazardous organic material, toxlcs, and/or radioactivity. It runs closely sirulating actual process type runs, the glass furnace effectively treated these hastes by degrading the salts to oxides that can be incorperated along with radioactivity and toxic retals into a highly stable glass ratrix. Most of the gaseous by-products of the waste treatment can be handled by a het of fgas scrubbing system. Tho major exceptions are Nox and volatile organics. This study has provided additional evidence that hox can be adequately controlled by means of the adding $\mathrm{NH} 3$ to the gases in the furnace chamber. To prepare glass with optimum characteristics, tatch compositions were computer selected for this study. The quantities of glass-making chemical adjitives required to prepare glass to this fornulation effectively eliminated any process volume reduction potential

for sore of the wastes. 1 ref., 17 flgs., 20 tabs. (ERA citation 13:035828) Descriptors: tChenical Effluents; Lon-Level Radioactive wastes: Madioactive Effluents; Evaluation: "Glass; Liquid fiastes; Nitrogen Oxides; - Otf-Gas Systems; Potassium Compounds; Radioactive liaste Managenent: Radicactive Waste frocessing: Rocky Flats Plant; Sodium Nitrates: Solidiflcation: Vitrification: Waste forms

Identiflers: ERDA/052001; ERDA/053000; Ammonia; NTISDE

Section Headings: $77 \mathrm{G}$ (fuclear Sclence and Technology--Radioactive wastes and Radioactivity): $68 \mathrm{~F}$ (Environmental pollution and cortrol--Radiation Follution and control): 710 (Materlals sciences--Ceranics, Refractories, and Glass)

2/5/39 (Iten 3 from flle: 6)

$1408213 \quad$ PB39-206031/XAB

Applications Analysis Report: Hacon solidification process,

Douglassville, Pennsylvana

saijer, $s$.

Foster Wheeler Envirestonse, Inc, Livingston, WJ.

corp. Source cotes: 09:973000:

sponsor: Hazco:, Inc., Haty, TX.; Environmental protection Ajency,

Cincinnati, CH. RISt Reduction Engineering Lab.

Fepo:t Ro.: EPA $540 / A 3-39 / 001$

$\therefore a ; \& 9 \quad 6 i p$

Languajes: English

Jowrnal Announcerent: GPAl3920

Also arailable fron Supt. of Does. See also pasj-153010. Prepared in

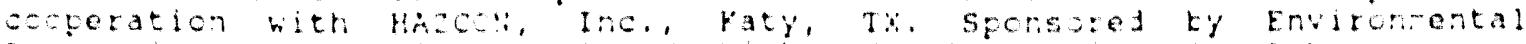

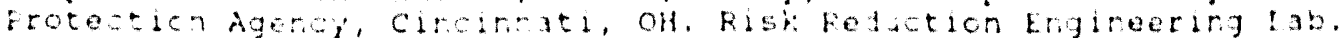

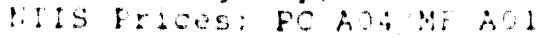

coutri of lublicat in: lasted states

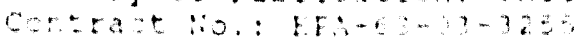

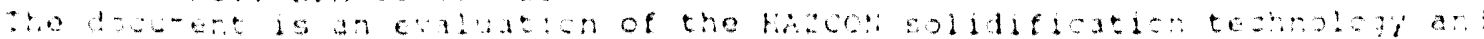

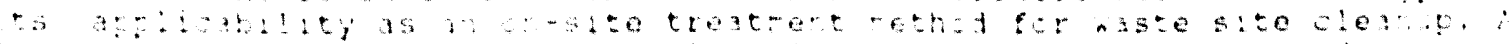

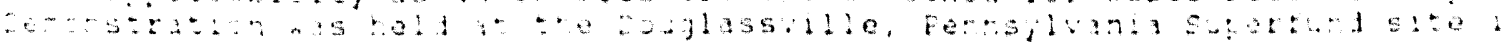

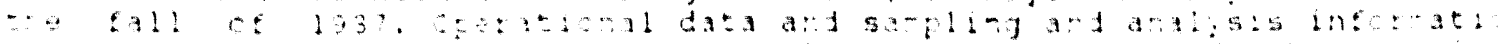

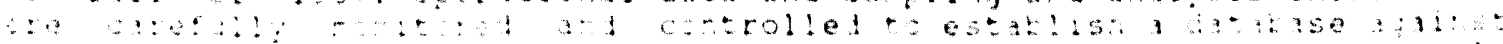

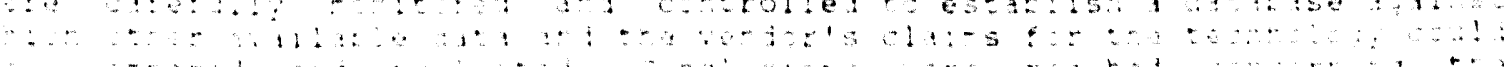

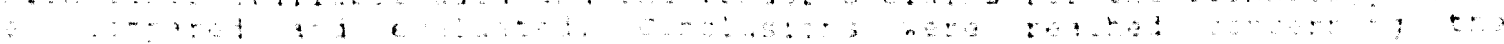


technology's sultability for lise in clean up of the types of raterials tound at the test ite, and extrapolations here made to cleanups of other -aterials.

Descriptors: Hazardous materials; cost analysis; "Solidification: - srcapsulating: Performance evaluation: Substitutes; Cements; Soll analysis ; Ferreability; Equlprent; soll stabilization: Leaching; Labage; sarpling Identiflers: isuperfund profect: sIIE progran: oll pollution; Evironental transport; Volatile organle compounds; leavy retals; land Follution: HTISGPO

section Headings: $68 \mathrm{C}$ (Environmental pollution and control--solid liastes Follition and Control): $97 \mathrm{R}$ (Energy--Environmental studles); $97 k$ (Erergi--ruels)

2/5/40 (Item 4 fron (110:6)

1383389 PB89-158828/XAB

Technolozy Evaluation haport s!TE program Denonstration Test, HAzCo:: Solidification, Douglassville, Pennsylvania. Volume 2

(Rept. for Ap: 87 -Aug 8 a)

Sanyer, $S$.

Enviresponse, Inc., Livingston, NJ.

Corp. Source codes: 087097000

Sponsor: Environmental Protection Agency, Cincinnat1, OH. Risk Reduction Engl neering Lab.

Report lio.: EPA/5\$0/5-89/001B

Feb $89326 \mathrm{p}$

Larguages: English

Journal Announcenent: GRAI8912

See also PB89-158810. Sponsored by Environmental Protection Agency, Cincinnati, OH, Risk Reduction Englneeiling Lab.

NTIS Prices: PC A15/MF A01

Country of Publication: United states

contract lio.: EPA-68-03-32.55

The rafor objectives of the HAZCON Solddifleation SITE program cenonstration Test here to develop reliable performance and ccst information. The ain?col process mixes the hazardous waste material with cerent, a proprietary additive called chloranan and water. The chloranan 1 s claimed to neutralize the inhiblting effect that organics nornally have on the hydration of cement. The technical criteria lises to evaluate the eftectiveness of the Hazcoll process here contaninant robllity based on leachirg and perneabllity tests; and potential integrity of solidified solls, based on measurenents of phisical and microstructural properties. E.tensife sappling and analyses weze performed showing the concentration of Ene orgarics were the same in the leachates of the untreated and treated solds, Pav retals reductions here achieved, and structural propertes o: the sol:jified cores here fcund to ir.ticate good long-tern stablity. The Ylute contais data collected during the profect.

Cescritces: Mazardous raterials; Cost analysis: Encapsulatirgi 011 astes: Salidification; Verforrance evaluation; Substitutes: cerents: soil amalysis: Soll stabilization; Concentration(Composition): Leaching: leabage : Dru-s(Ccntainers): Sarplirg; Tables(Cata)

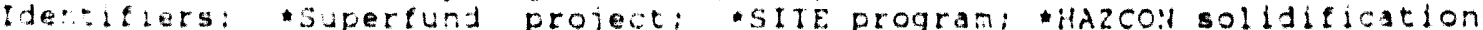

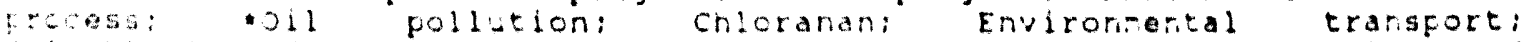
Ljaloritated biphenyls; Yolatile ozganic corpounds; beary retalsi Lard

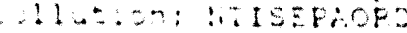

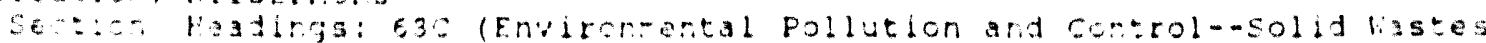

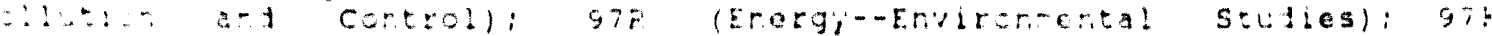
$\left.\div a x_{1},-501 s\right)$

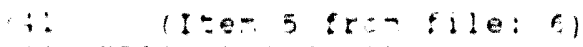

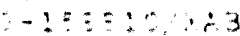


Technclogi Evaluation Report SITE Prograr Deronstration Test, MÄCo: solidification, Douglassville, Pennsylvania, Volute 1

(Rept. Cor Apr B7-Aug 68 )

Sainjer, S.

Eriviresponse, Inc., LIVIngston, NJ.

Corp. Source codes: 087097000

Sponsor: Environtental Protection Ageney, Cincinati, Ot. office of Sesearch and Development.

Peport 110.: EPA/540/5-39/101A

Feb $89 \quad 131 \mathrm{p}$

Largiages: English

Journal Announcement: GRAI8912

see a 1 so PB39-158828. Sponsored by Environmental protection igency,

circinnati, $O H$. Offlce of Researcil and Developrent.

litis Prices: PC AO7/MF AOI

Country of Publication: United states

Contract No.: EPA-6B-03-3255

The major objectives of the HAzcon solidification sile prograi Demonstration Test were to develop rellable performance and cost information. The HAzCON process mixes the hazardous waste material with cerent, a proprietary additive called chloranan and water. The chloranan is clained to neutralize the inhiblting effect that organics normally have on the hydration of cement. The technical criterla used to ovaluato the effectiveriess of the Hazco:l process were contaminant nobility, tased on leaching and permeablilty tests; and potential integrity of solidifled soils, based on, measure-ents of physlcal and microstructural projerties. Extensive sarpling and analyses rere performed showing the zoncentration of tre organics were the same in the leachates of the untreated and treated solls, heavy metals reductions were achleved, and structural prcperties of the solidified cores were found to indleate good long-tern stabliti.

Descriptors: Hazardocs naterlals; Cost analysis: Encapsulatirg: *011 wastes; Solldification: Performance evaluation; Substitutes; Cenents; soll aralysis; soll stabilization: Leachlng; Learage: Drums(contalners): sarpling

Identiflers: \$S:perfund project: SITE program: hizCON solidification process: oil pollutica; chloranan; Environertal trasport; polychlorinated biphenjs: Volatile organic corpounds; Heavi retals; Larid pollution; liIISERrol?

section Headings: 6ec (Environertal pollution and control--solid liastes follution and control); $97 \mathrm{R}$ (Energy--Environmental studies): $97 \mathrm{k}$ (Energj--Fuels)

?t $2 / 5 / 1-3$ fren 340

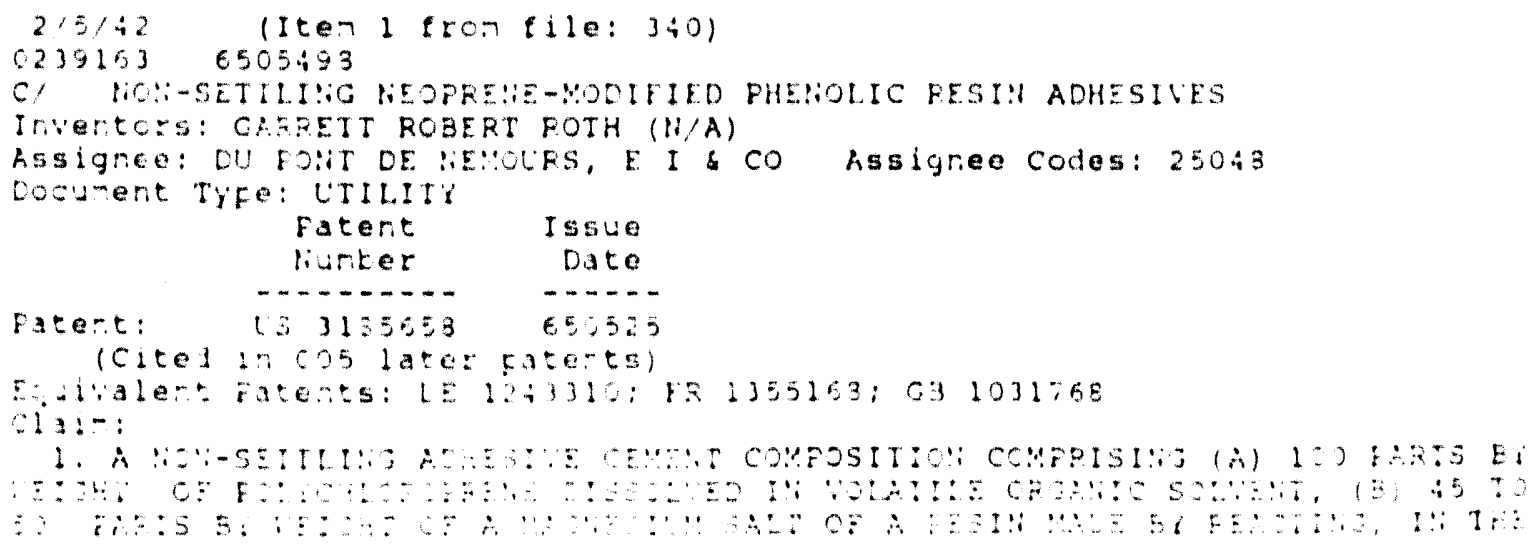




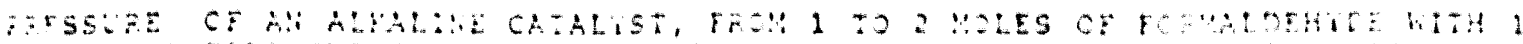

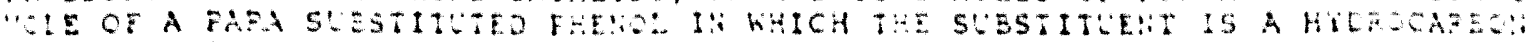

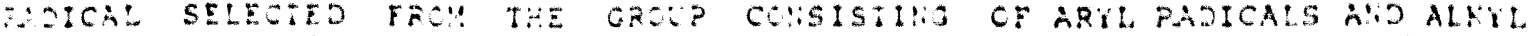

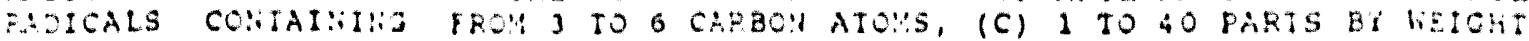

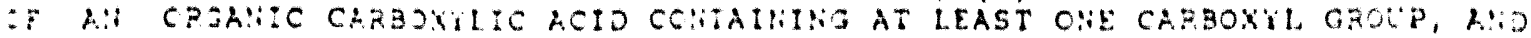

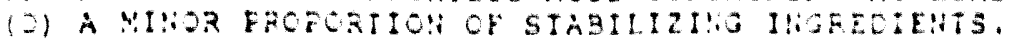

SA Fet: 62004173

:Iss: $524+32000$

Cross Fef: 524284000; 524237020; 524300000; $524432000 ; 525139000 ; 525506000$ ib 411 


\section{INTERNAL DISTRIBUTION}
1. J. B. Berry
2. W. D. Bostlck
3. C. H. Brown
4. A. O. Croff
5. T. L. Donaldson
6. C. L. Francis
7. R. K. Genung
8-12. T. M. Gilliam
13. H. W. Oodhec
14. H. M. Henson
15. K. H. King-Jones
16. A. P. Malinauskas
17. E. W. McDanicl
18. I. L. Morgan
19. S. C. Oshorne

\author{
20. S. M. Robinson \\ 21. M. K. Savage \\ 22. J. L. Shoemaker \\ 23.27. R. D. Spence \\ 28. O. K. Tullent \\ 29. D. R. Trotler \\ 30. J. E. Williams \\ 31. J. H. Wilson \\ 32. Ceniral Rescurch Library \\ 33. ORNL Y.12 Technical Lihrary, \\ Document Reference Seclion \\ 34. Laboratory Records - RC \\ 35.36. Laboratory Records \\ 37. ORNL Palent Section
}

\section{BXTERNAL DISTRIBUTION}

38. J. J. Barich, U.S. Environmental Protection Agency, 12(x) Sixth Avenue, Seatlle, Washinglon 98101

39. J. Bradford, EG\&G Idaho, Inc., P.O. Box 1625, Idaho Falls, Idaho 8.3415-21(x9

4). K. C. Burgard, Wesilinghouse Hanford Company, P.O. Box 1970, Richland, Washington 99352

41. J. Cwynar, West Valley Nuclear Services Company, Inc., P.O. Box 191, West Valley, New York 14171-(0191

42. T. T. Holmes, U.S. Army Corps of Engineers, Waterways Experiment Stalion, P.O. Box 631, Vickshurg, Mississippi 39180)

43. A. J. Johnson, EG\&G Rocky Flats, P.O. Box 464, Golden, Colorado \$(1)4(1)2-(1)464

44. C. A. Langion, Westinghouse Savannah River Company, P.O. Box 616, Alken, South Carolina 29802

45. J. W. Liskowitz, Institute for Hazardous and Toxic Waste Management, New Jersey Institute of Technology, Newark, New Jersey 07102

46. R. O. Lokken, Battelle, Pacific Northwesi Laboratories, Batlelle Boulcvard, Richland, Washington 99.352

47. R. J. Murkowski, Westinghouse Hanford Company, P.O. Box 1970), Richland, Washington 99352

48. O. Ricbling, Westinghouse Hanford Company, P.O. Box 1970), Richland, Washinglon 99.352

49. G. W. Veazcy, Los Alamos National Laboratory, P.O. Box 166.3, MS E.524, Los Alamos, New Mexico 87545

50. J. H. Westsik, Jr., Batlelle, Pacific Northu si Laboratorics, Ballelle Boulevard, Richland, Washington 99352

51. C. C. Wiles, Risk Reduction Enginecring Laboratory, U.S. Environmental Protection Agency, 26 West Martin Luther King Drive, Cincinnati, Ohio 45268

52. Office of Assistant Manager, Energy Research and Development, DOE.ORO, P.O. Box 2(x)1, Oak Ridge, Tennessec 378.31

53-54. Office of Scientific and Technical Information, Oak Ridge, TN 378.31 


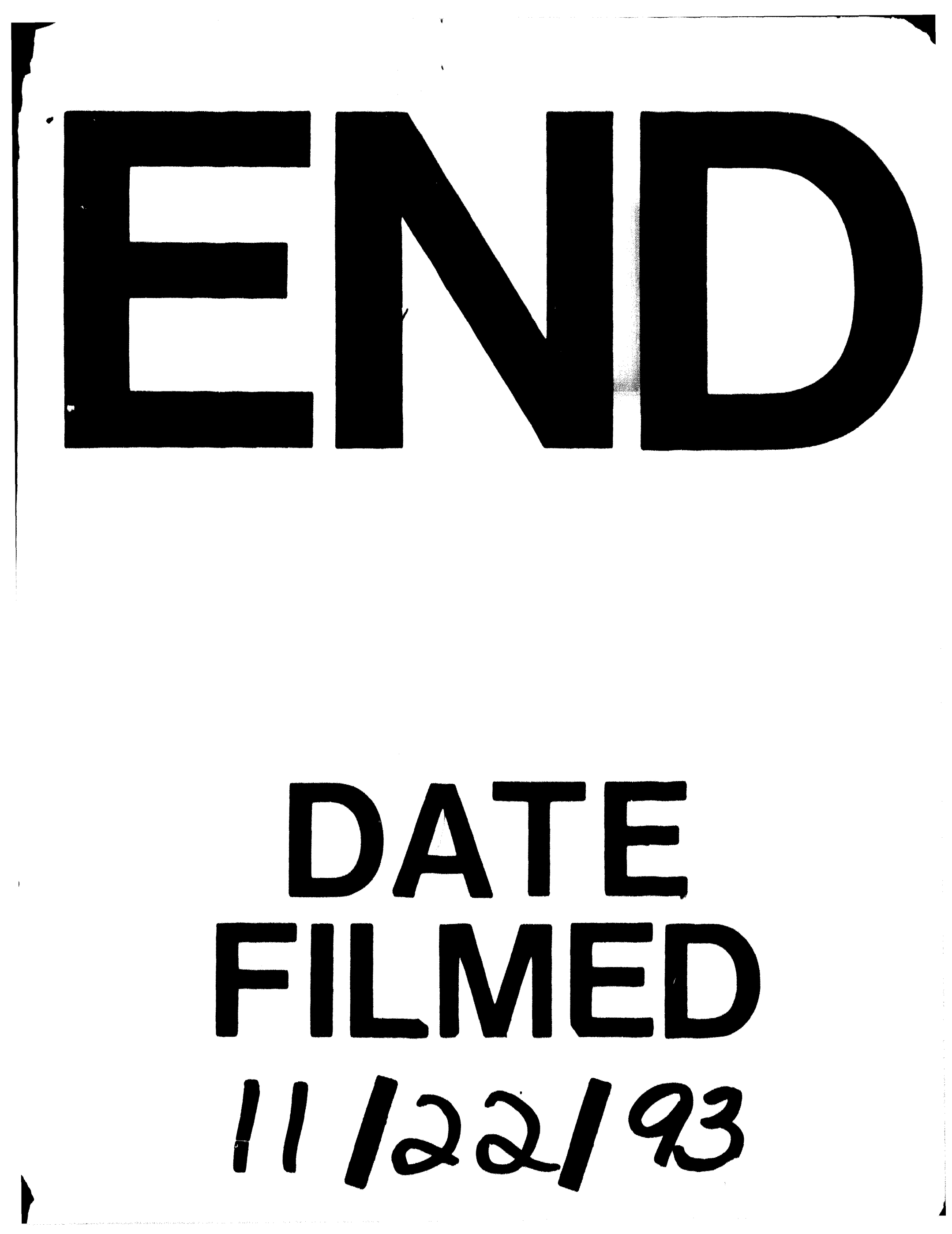


